\title{
Alternative Inspection Methods for Single Shell Tanks
}

TJ Peters

JM Alzheimer

DE Hurley

January 2010

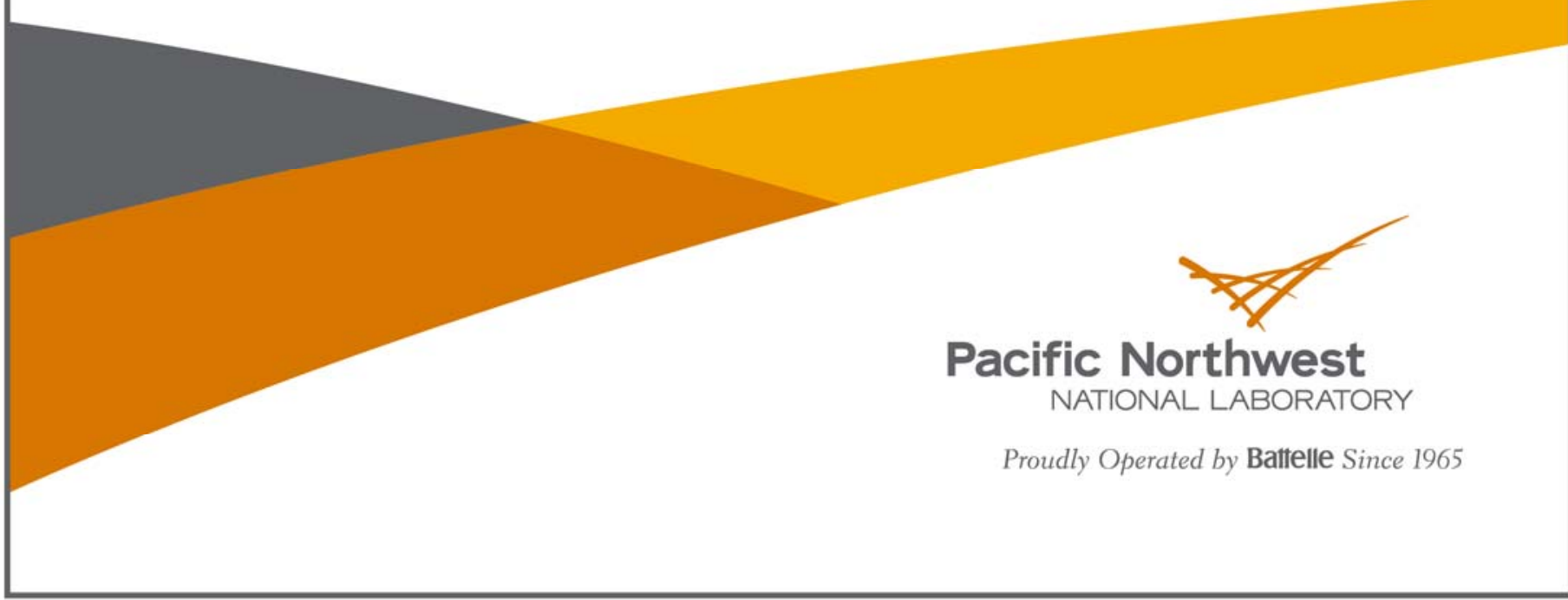




\section{DISCLAIMER}

This report was prepared as an account of work sponsored by an agency of the United States Government. Neither the United States Government nor any agency thereof, nor Battelle Memorial Institute, nor any of their employees, makes any warranty, express or implied, or assumes any legal liability or responsibility for the accuracy, completeness, or usefulness of any information, apparatus, product, or process disclosed, or represents that its use would not infringe privately owned rights. Reference herein to any specific commercial product, process, or service by trade name, trademark, manufacturer, or otherwise does not necessarily constitute or imply its endorsement, recommendation, or favoring by the United States Government or any agency thereof, or Battelle Memorial Institute. The views and opinions of authors expressed herein do not necessarily state or reflect those of the United States Government or any agency thereof.

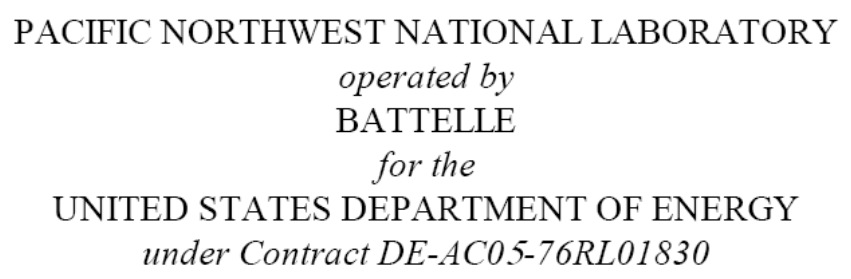

Printed in the United States of America

$$
\begin{gathered}
\text { Available to DOE and DOE contractors from the } \\
\text { Office of Scientific and Technical Information, } \\
\text { P.O. Box 62, Oak Ridge, TN 37831-0062; } \\
\text { ph: (865) 576-8401 } \\
\text { fax: (865) 576-5728 } \\
\text { email: reports@adonis.osti.gov }
\end{gathered}
$$

\footnotetext{
Available to the public from the National Technical Information Service, U.S. Department of Commerce, 5285 Port Royal Rd., Springfield, VA 22161 ph: (800) 553-6847 fax: (703) 605-6900 email: orders@ntis.fedworld.gov online ordering: http://www.ntis.gov/ordering.htm
}

Electronic copies of the report are also available from the DOE Solid State Lighting website at http://www.netl.doe.gov/ssl/techdemos.htm.

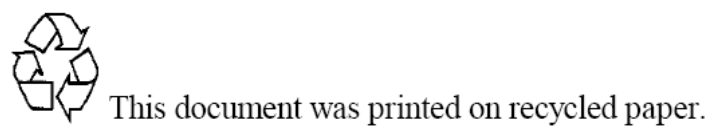

$(9 / 2003)$ 


\section{Alternative Inspection Methods for Single Shell Tanks}

TJ Peters

JM Alzheimer

DE Hurley

January 2010

Prepared for the U.S. Department of Energy under Contract DE-AC05-76RL01830

Pacific Northwest National Laboratory

Richland, Washington 99352 


\section{Contents}

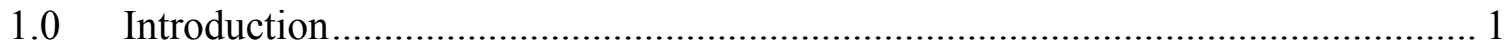

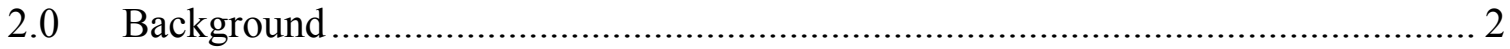

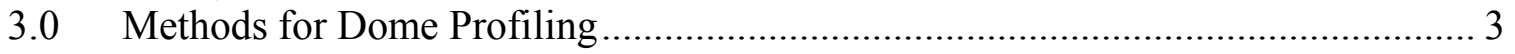

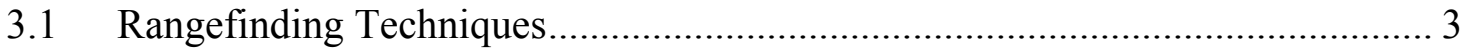

3.2 Optical Phase Detection Technique ........................................................... 7

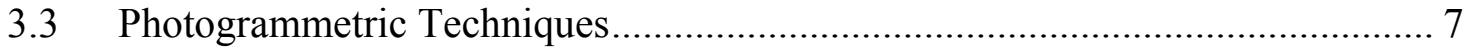

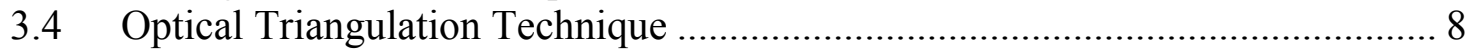

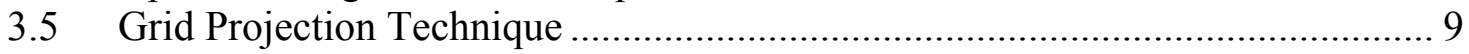

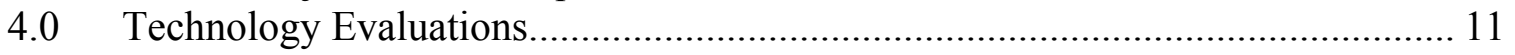

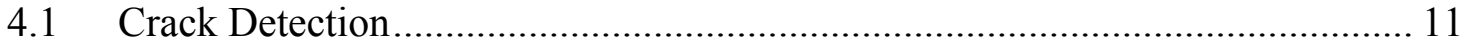

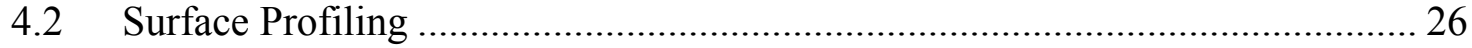

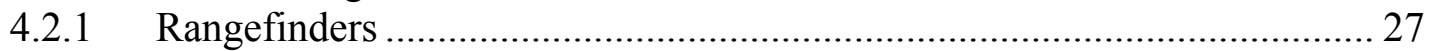

4.2.2 Optical Phase Technique ...................................................................... 29

4.2.3 Photogrammetric Techniques............................................................... 29

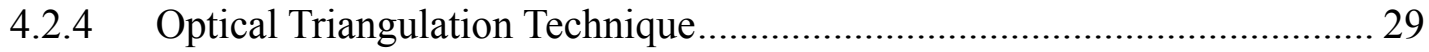

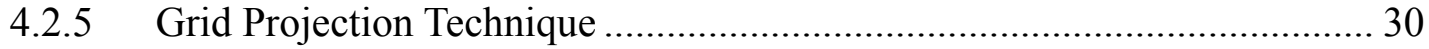

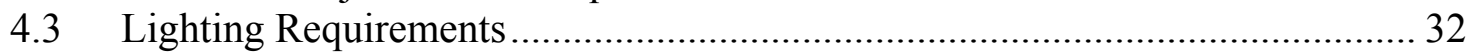

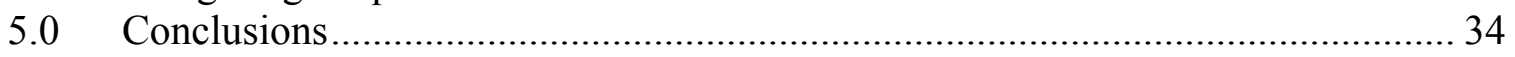

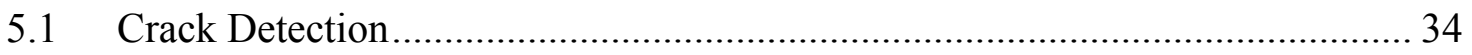

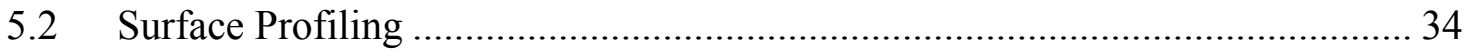




\section{Figures}

Figure 1: Assumed Waste Tank Dimensions................................................................. 4

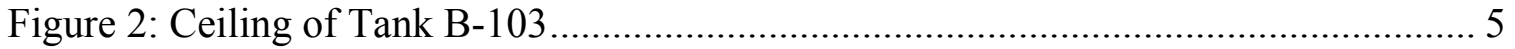

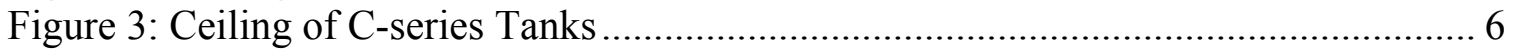

Figure 4: Principle of Optical Triangulation Technique............................................... 9

Figure 5: Pictures of Concrete Specimens with Resolution Equivalent to a High-

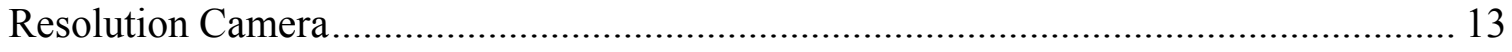

Figure 6: Effect of Various Lighting Schemes on Crack Detection .............................. 15

Figure 7: Effect of Polarization of Light on Image of Crack........................................ 16

Figure 8: Effect of Image of Crack as a Function of Longer Wavelengths ..................... 17

Figure 9: Effect of Image of Crack as a Function of Longer Wavelengths ..................... 18

Figure 10: Effect of Light Source Angle on Crack Detection ...................................... 19

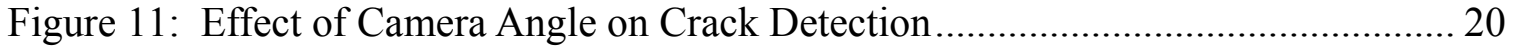

Figure 12: Effect of Image Compression Techniques on Crack Detection..................... 22

Figure 13: Effect of Applying Image Filters on Crack Detection (A) ........................... 23

Figure 14: Effect of Applying Image Filters on Crack Detection (B) .......................... 24

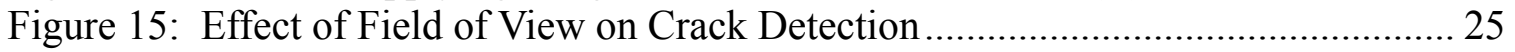

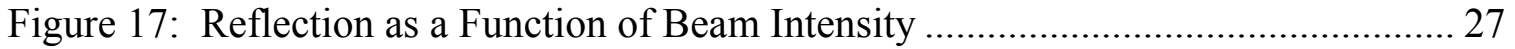

Figure 18: Reflected Signal as a Function of Gap Size .............................................. 28

Figure 19: Reflected Signal from Rough Concrete................................................... 29

Figure 20: Possible Deployment Scheme for a Remote Measurement Gage ................. 26

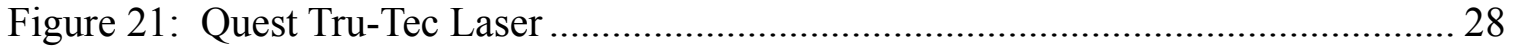

Figure 22: Laser Triangulation Technique on Rough Concrete at 38 Degree Angle....... 30

Figure 23: Grid Projection Technique (30 Degree Angle) ......................................... 31 


\subsection{Introduction}

The research discussed in this document was funded under DOE's EM-20 Support Program's Waste Storage Reutilization Study Project. This document provides evaluations and recommendations regarding nondestructive evaluation methods that might be used to determine cracks and bowing in the ceiling of waste storage tanks on the Hanford site. The goal was to determine cracks as small as 1/16 in. wide in the ceiling and bowing as small as 0.25 in. This report describes digital video camera methods that can be used to detect a crack in the ceiling of the dome as well as profiling methods for determining the surface topography of the ceiling and thereby detecting localized movements in the surface. A literature search, combined with laboratory testing, comprised this study. The methods evaluated were:

A. Crack Detection:

- Video imaging methods can be used to enhance crack detection in the dome of a waste tank.

B. Profiling:

- Rangefinder Techniques - a beam is projected onto the surface, and the time of flight is measured to determine the position of the surface. The beam could be acoustic (sound) energy, light, microwave (radar) energy, or energy in the millimeter wavelength region.

- Optical Phase Detection Technique - the phase shift is measured in a modulated laser beam reflected from the surface.

- Photogrammetric Techniques - the distance to various surface features is determined by analysis of a series of photographs taken from different positions. Also included is the stereoscopic method, in which the depth to a surface feature is determined and viewed by separating two cameras a known distance.

- Optical Triangulation Technique - a laser beam is scanned across the surface of the contents, and the light reflected from the surface is received by a detector.

- Grid Projection Technique - lines are projected onto the top surface of the tank contents, and their shape indicates the contour of the surface.

Commercial system suppliers of these methods were contacted to determine if they could meet the waste tank requirements. Laboratory tests were conducted on some of the most promising techniques to evaluate their feasibility and limitations. 


\subsection{Background}

The typical configuration of a double-shell waste tank is shown in Figure 1. Each tank is approximately $75 \mathrm{ft}$ in diameter and $55 \mathrm{ft}$ high. The surface level of the contents is usually about $30 \mathrm{ft}$ below the top of the tank when full.

Photographs have been taken inside the waste tanks since the 1970's. Originally, a Hasselblad 500 EL camera (120-mm format) was used with a 2400 watt-second strobe light and a 0.002-sec flash duration. A composite image was made by taking twelve photographs, each at 30-degree intervals, at three deployment angles. The camera field of view was 500, with the three deployment angles set at 200, 500, and 800 below horizontal. The focus and F-stop for the camera were set manually at the surface using a chart that shows the camera angle and distance from the waste surface. A few stereophotographs have been taken inside the tank by moving the Hasselblad camera from one side to the other of the 12-in riser. These were then viewed with a stereoscope. No further analysis of the pictures was performed other than visual observation.

Currently, a GE Inspection Technologies digital remote camera is used to take pictures inside the waste tanks. The advantage of this system is that it can be viewed in real time. However, it does not have the resolution to detect cracks $1 / 16$ inch wide in the ceiling nor measure bowing in the ceiling. Figures 2 and 3 show pictures of a waste tank ceiling taken with this camera.

Camera equipment capabilities are constrained by the location of tank penetration ports. For the purpose of this study, it was assumed that the distance from the bottom of the riser to the top of the surface contents was 14 to 20 feet, so a 10- to 12-foot photograph distance was used, since any system should extend beyond the bottom of the riser. The existing risers range up to 48 inches in diameter, but emphasis was placed on instruments that would fit into a 12-in diameter riser. The distance from the camera to the wall of the tank was assumed to range from $5 \mathrm{ft}$ to $60 \mathrm{ft}$. 


\subsection{Methods for Dome Profiling}

Various methods can be used to profile the surface of the dome in the waste tanks. Brief descriptions of several of these methods are provided in this section. A previous investigation by Pacific Northwest National Laboratory of dimensional profiling of underground storage tanks, mostly related to waste surface contours and heel volumes, is presented in "Evaluation of Methods to Determine Surface Topography for Waste Tank 101-SY," by T. J. Peters, F. M Cuta, and P. G. Szerszen.

\subsection{Rangefinding Techniques}

The principle of rangefinding techniques is that a signal carrier, such as acoustic or optical waves, is sent out from the measurement system, reflects off the object whose distance from the measurement system is to be determined, and returns to the sender. The signal carrier is assumed to travel with a known velocity, so that the elapsed time between when the signal is sent and when it is received determines the distance to the object. To get three-dimensional information, the signal beam must be scanned over the scene or object. The signal beam could be a single pulse, with a very short pulse width, or a chirp signal, which is a signal whose frequency varies linearly over the duration of the transmission. The signal carrier can be acoustic (sound) energy, light, microwave or radar energy, or in the millimeter wavelength region. Haze in the tanks could be a problem if the light energy is in the visible region, but if the infrared wavelength region is used, the amount of energy transmitted through the haze can be greatly increased. The other signal carriers are not as affected by haze or fog in the tanks.

For short distances, the electronics needs to be extremely fast in order to detect the time between when the energy is sent to when it is received. In order to overcome this problem, the frequency of the signal can be varied as a function of time. This approach allows for measuring short distances very accurately within a large measuring range. Sometimes, instead of detecting the time of flight, the operation of the rangefinder is changed so that subsequent pulses are sent out only after the previous pulse is received, and then the number of pulses sent out by the measurement system in a given time period is related to the distance to the object. 


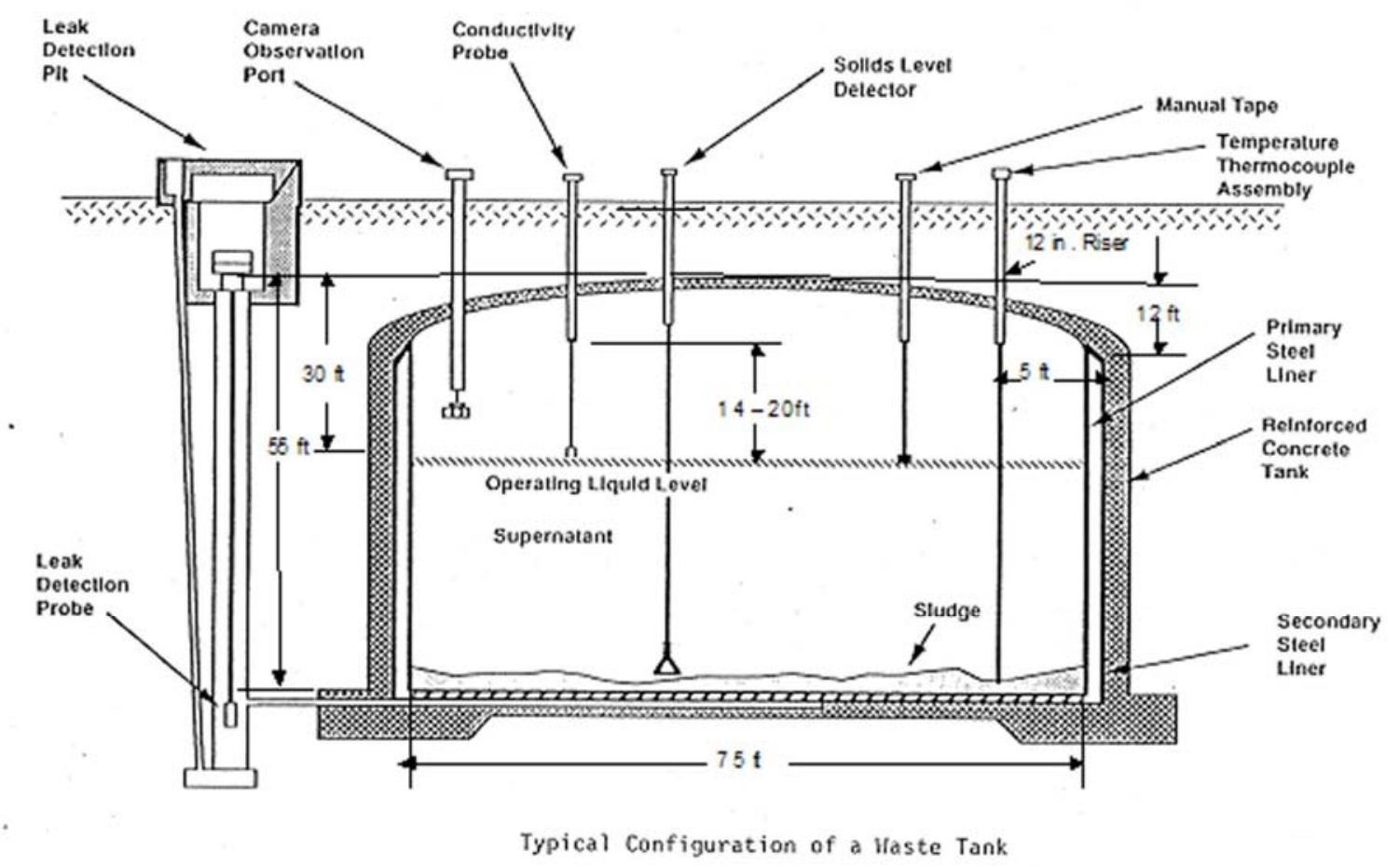

Figure 1. Assumed Waste Tank Dimensions 


\section{In-Tank Photography - Concrete Dome}

\section{B-103 Concrete Dome (Type 2 - 100 Series Tank) - 1988}

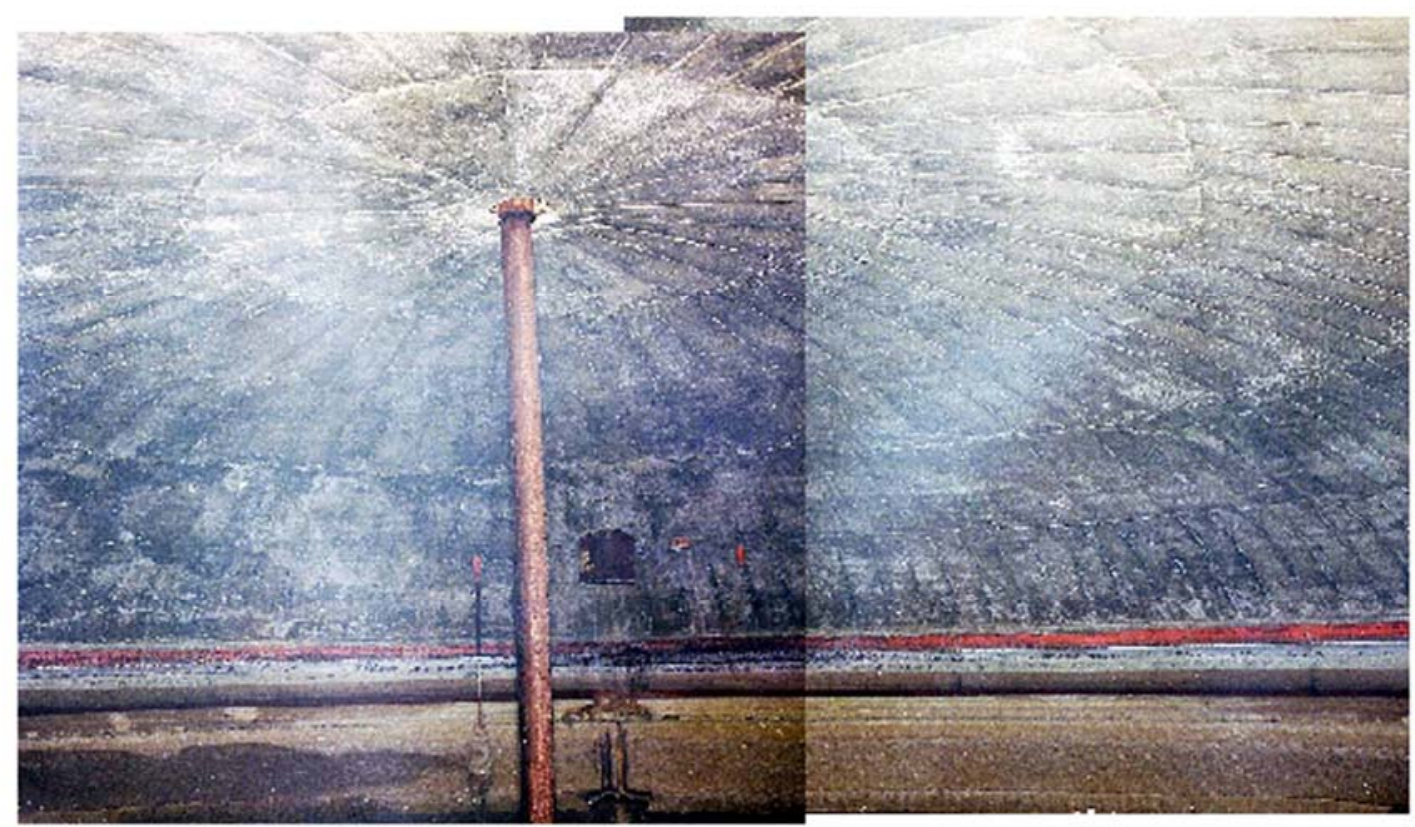

Figure 2. Ceiling of Tank B-103 


\section{In-Tank Photography - Concrete Dome}

\section{C-203 Concrete Dome Type 1-200 Series Tank}

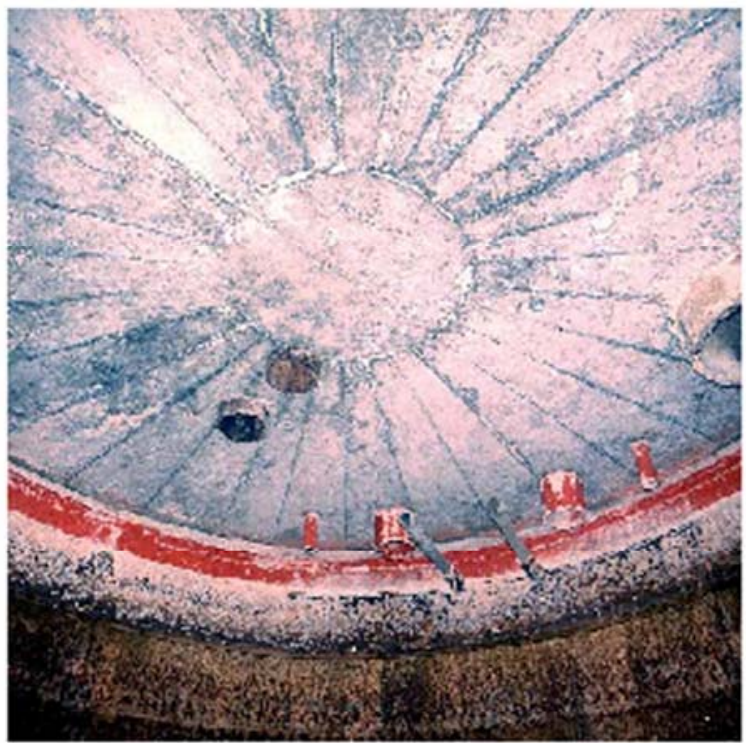

C-201 Concrete Dome

Type $1-200$ Series Tank

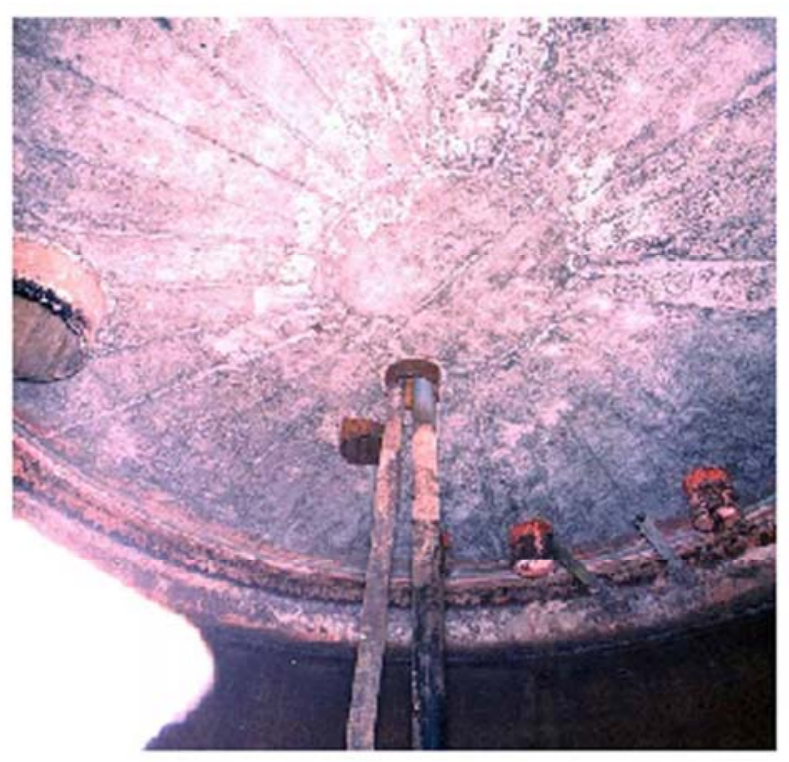

Figure 3. Ceiling of C-series Tanks 


\subsection{Optical Phase Detection Technique}

An optical phase detection system measures the phase shift between the output beam and the beam reflected from the object. The output beam is modulated, either in frequency or amplitude. The signal reflected from the target has travelled a much longer path, and when it arrives at the detector it is shifted in phase from the initial beam. The amount of this phase shift is proportional to the distance to the object.

This technique's advantage is that it is not dependent on the intensity of the received signal. As long as the reflected signal has a high enough amplitude to be combined with the initial signal, the range can be detected. As with the frequency modulated rangefinder technique, short distances can be measured very accurately. Unlike the optical triangulation technique, the accuracy is not a function of the separation between the scanner that is placing the strip of light on the surface and the receiver. The disadvantage of the optical phase detection technique is that the system can only be used to measure small area changes in the surface contour, e.g., $10 \mathrm{ft}$ with a simple laser diode. This means the system needs to be mounted on a robotic arm in order to measure a large area like the surface of a waste tank. Discrete points or areas directly under a waste tank riser can also be monitored with this technique. The range over which this system will operate is a function of the coherence length of the laser, the sensitivity of the detector, and the reflectivity of the target surface.

\subsection{Photogrammetric Techniques}

The process of obtaining surveys by means of photography is known as photogrammetry. Several photographs of an object are taken from different angles, with each of the photos containing two or more of the same points on the object, as well as a reference point that has been independently measured. The photographs are then analyzed by digitizing selected points on the object after being placed on an x-y plotter. A computer program then automatically analyzes the coordinates of the selected points. Most of this work, due to its simplicity, can be completed with a desktop personal computer. The advantages of this technique are that the procedures being used for taking pictures in the waste tanks can be utilized - although a different camera selection would be needed - and it does not involve placing sophisticated electronic components in the harsh waste tank environment. The disadvantage of this technique is it cannot be used if there is a substantial amount of haze in the atmosphere in the tanks. 


\subsection{Optical Triangulation Technique}

Optical triangulation is a common method used to measure the distance to an object. The principle is illustrated in Figure 4. When the light from a source, such as a laser, is reflected from the surface to be inspected and imaged onto a detector array, certain elements in the array become illuminated and output a voltage. When the object is displaced, or a point on the object is displaced from another point, the reflected light is imaged to a different position on the array, which means a different set of elements of the array will be lighted. By knowing the magnification of the system, the displacement or size of the object can be determined. In order to determine the profile of a large object, the source and detector are mounted in a unit that scans the object.

This is one of the oldest techniques for profiling objects, and the invention of the laser allows for accurate profiling at large distances. However, the accuracy is dependent on magnification of the system. The detector can only be a finite length, so the amount of the surface that can be seen at any one time (the field of view of the optical system) is dependent on the size of the detector element and the desired accuracy. One way to minimize this problem is to place a scanning mirror in the receiver and synchronize its movement with the corresponding movement of the scanning mirror in the transmitter. 


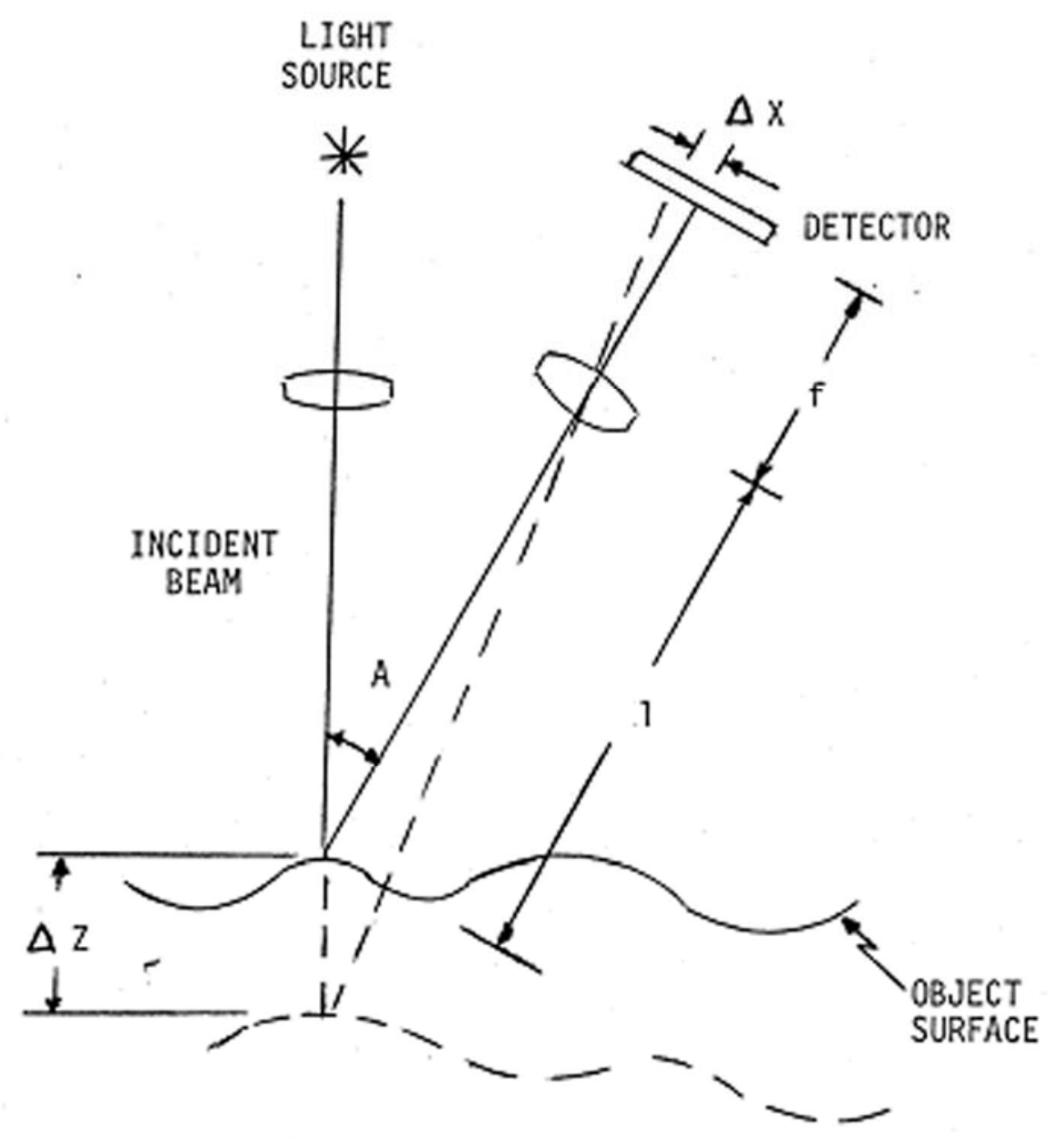

Figure 4. Principle of Optical Triangulation Technique

\subsection{Grid Projection Technique}

A coarse grating, e.g., 200 lines per inch, can be projected onto a surface, and a shadow of the grating will follow the contour of the surface. When this grating is viewed through another grating in the detector plane (a reference grating), a beat pattern is established between the projection of the master grating on the surface and the reference grating. Any change in the object results in a change in the viewed fringe pattern. This technique, known as Moire projection, generally provides differential range information rather than absolute range information. Given the projection and viewing geometries, the amount of change in the surface can be quantified.

The advantage of this technique easily shows the contour of the surface. A television camera could be placed behind the reference grating to view the pattern. It may be possible to use a fiber optic bundle to bring the image to the surface, so that the 
only items required in the tank are the gratings, the light source and the fiber optic cable. A disadvantage of the technique is that the resultant fringe pattern is difficult to interpret. Several techniques for automated analyses of fringe patterns have been developed. A high area and a low area will both appear the same in a Moire pattern. But, as will be discussed later in this report, there are simple techniques to resolve this problem.

An alternative method, that is a combination of the laser triangulation technique and grid pattern projection technique that could be applicable for the measurement of surface contour in waste tanks is to project and scan a laser beam across the surface of the contents and view the reflected light in a time exposed photograph. The resultant photograph would be a grid pattern that follows the contours of the surface. Changes in the surface would result in changes in the grid pattern, which could easily be determined by comparing the two photographs. 


\subsection{Technology Evaluations}

\subsection{Crack Detection}

A high-definition video camera only has about two megapixels. A typical array is 1920 x 1080 pixels. Although this is about four times better then the system presently being used, a professional digital camera can achieve 15 megapixels (4752 x 3168 pixels). An example is the Canon EOS 500D. It has low resolution video output, which would allow the operator to determine the location being shot, and then take individual shot with the high-resolution still photos. It may also be possible to attach a small video camera to the viewfinder of a camera to determine the location, and then take highresolution individual shots.

If one wants to inspect the whole ceiling, and we assume the dome is 75 feet in diameter and twelve feet high, then the area to be inspected is $12,480 \mathrm{ft}^{2}$. At the minimum detection capability, a 1/16 in. crack must occupy two pixels widths in the image. Using this criteria, and assuming a 2/3 format camera (3168 pixels x 4752 pixels), the area in the field of view would be $102 \mathrm{ft}^{2}$. So at this camera resolution (15 megapixels), an analysis would need 122 images to inspect the complete dome.

The Canon EOS camera has an array that is $36 \times 24 \mathrm{~mm}$. A lens that would fill that array and the desired resolution would have a focal length of $175 \mathrm{~mm}$. The lens would have to be an automatically controlled zoom lens because the distance to the dome will change depending on what part of the dome one is observing but this is the maximum focal length needed to achieve the desired resolution at sixty feet.

Tests were conducted to look at various techniques that might be used to enhance the video image. The initial tests were done with a Kodak DC120 digital camera, which has 0.9 megapixels (1280 x 720 pixels). In order to achieve the equivalent resolution of a high-resolution camera from this camera, the field of view (FOV) was decreased to 22.5 inches. Two blocks were examined: a clean smooth red concrete block with a fractured crack in it, and a rough concrete block with a crack that does not go all the way through. The resulting image is shown in Figure 5. A larger image of the crack in the rough concrete block is also shown in Figure 5. These pictures were taken with room lights with an intensity of 142 lux on the face of the concrete slabs. As shown in Figure 5, with the equivalent resolution of sixty feet with a high resolution camera, a viewer can easily see the crack in the smooth block and just barely detect it in the rough block. 


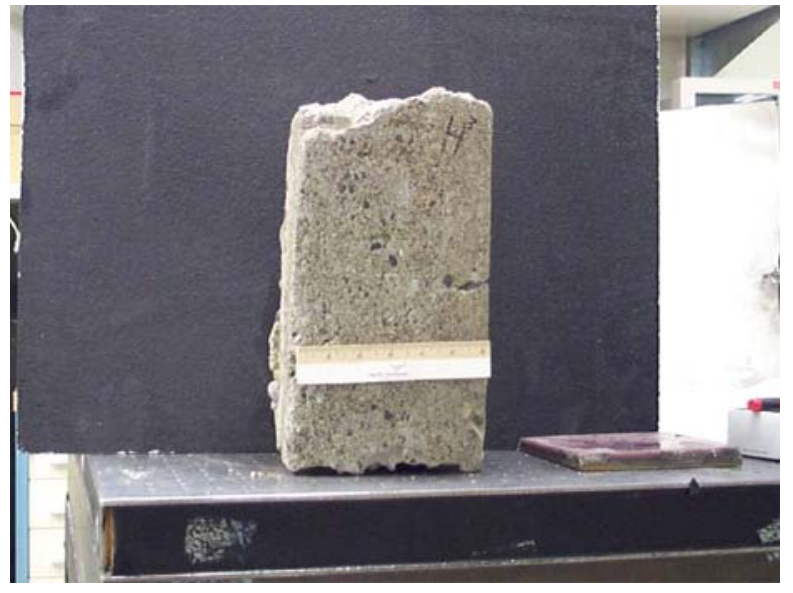

Figure 5a. Rough Concrete Block

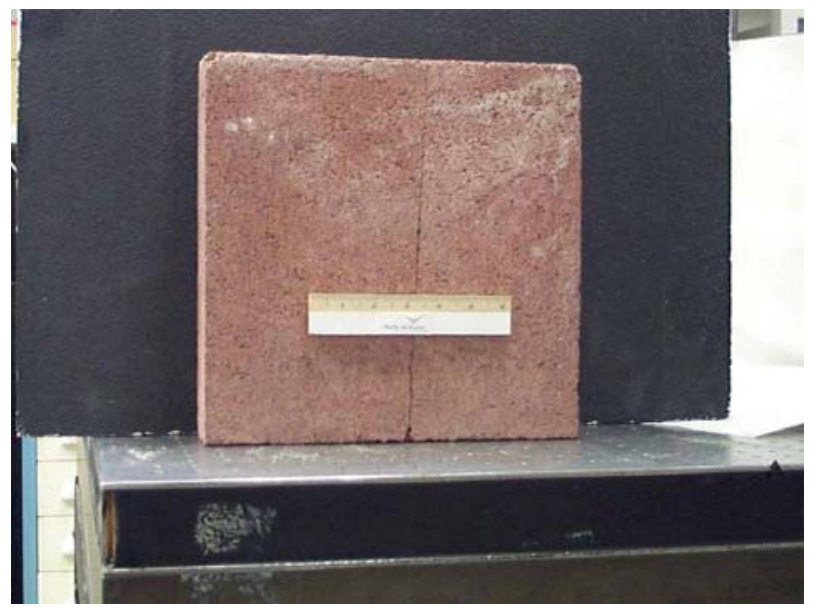

Figure 5b. Smooth Concrete Block

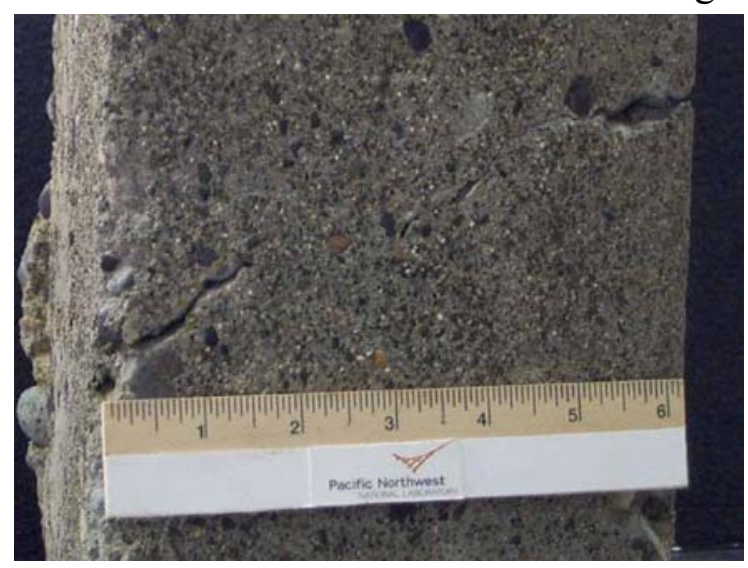

Figure 5c. Close Up of Crack in Rough

Concrete Block

Figure 5. Pictures of Concrete Specimens with Resolution Equivalent to a High-Resolution Camera 
Lighting is critical to any crack detection. Because the crack in the rough concrete block was harder to detect, it was used for most of the other tests. Figure 6 shows the difference between fluorescent diffuse light and tungsten light set at approximately 28 degree angle to the slab surface (the camera is at fourteen degrees from the perpendicular to the slab surface in the other direction). There is some enhancement noted from using directed light. A more thorough study of the effect of camera and light angle on the image will be discussed later.

Light reflected from a surface is slightly polarized. The effect of looking through a polarizing filter, and polarizing the light and looking at the object through a cross polarizing filter, is shown in Figure 7. The effect of polarization is a function of the angle, with more of an effect with sharper angles. However, viewing the image at different angles did not significantly change the result that polarization did not significantly enhance the crack.

The silicon sensor in a camera has is able to detect energy from the ultraviolet (300 $\mathrm{nm}$ ) to the near infrared (one micron). The effect of different wavelengths (color) of the incident light was also tested. Figure 8 shows the effect of using longer wavelength energy (near infrared to middle infrared). The middle infrared image ( 3 to 5 microns) was taken with an infrared camera which has fewer pixels (256 pixels x 256 pixels) than the digital camera The hypothesis in using infrared wavelengths was that it would smooth the rough surface and perhaps enhance the dark crack. As the results in Figure 8 show, the infrared wavelengths also smoothed the crack, so it was at best no better than the visible image.

A test was conducted toward the ultraviolet end of the spectrum. The results are shown in Figure 9. Again, there does not appear to be any significant gain by going to the shorter wavelengths. In addition, it significantly increased the exposure time because the silicon sensor in the camera is less sensitive at these wavelengths.

The effect of camera and light angle on detecting the crack was investigated. The results are shown in Figures 10 and 11 and indicate that increased lighting angle will enhance flaw detection.

There are other parameters that will effect crack detection. For example, in order to save room on the storage media, the digital image is compressed. There are various methods to compress an image, the most common being the .tif and .jpg image formats. In addition, individual cameras may contain their own compression formats. The effect of these various compression formats on detecting the crack in the concrete was tested, 


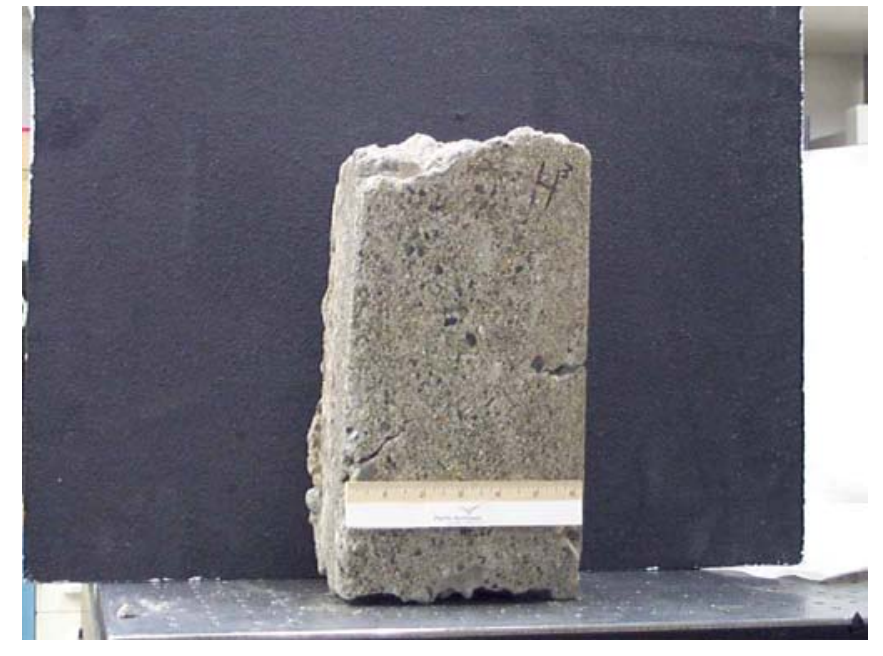

Figure 6a. Diffuse Fluorescent Light

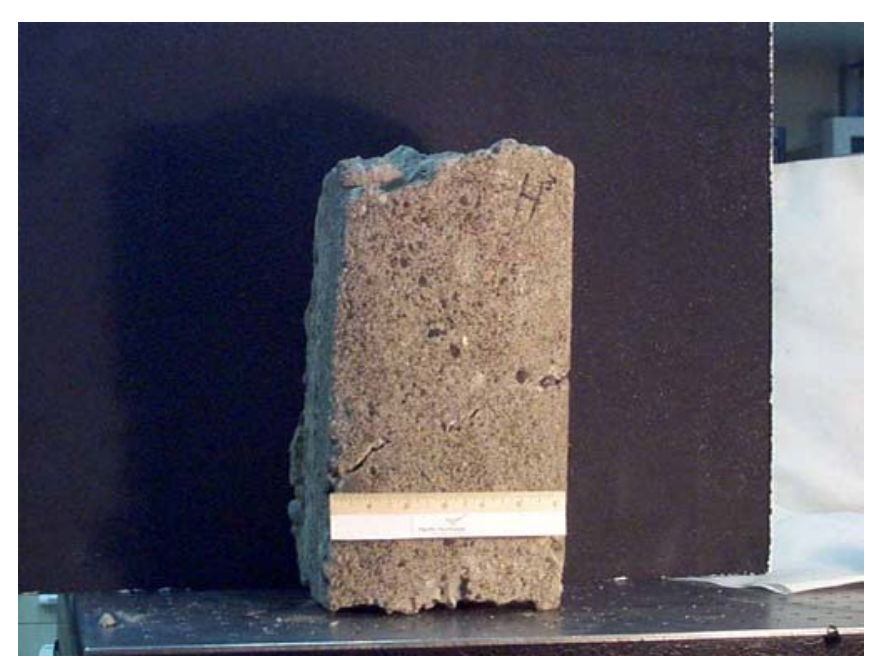

Figure 6b. Tungsten Light Source

Figure 6. Effect of Various Lighting Schemes on Crack Detection 


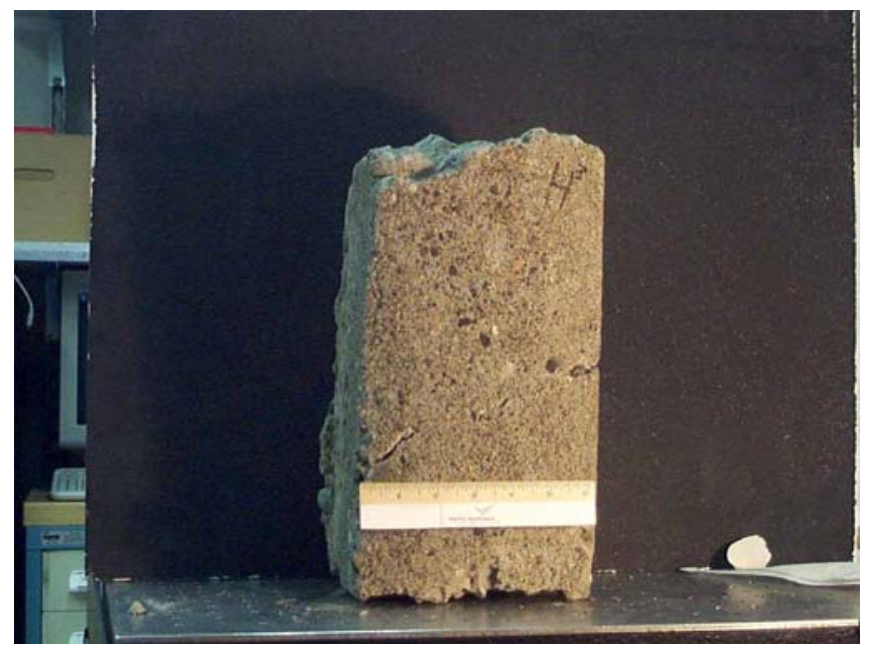

Figure 7a. Polarizing Filter in Front of Camera

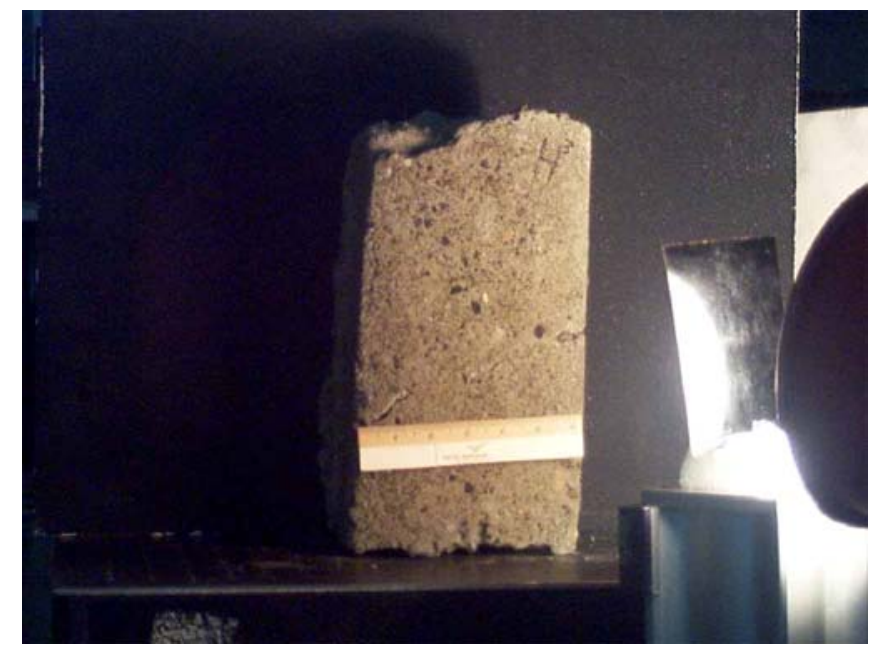

Figure 7b. Cross Polarization with Light Source

Figure 7. Effect of Polarization of Light on Image of Crack 
Visible

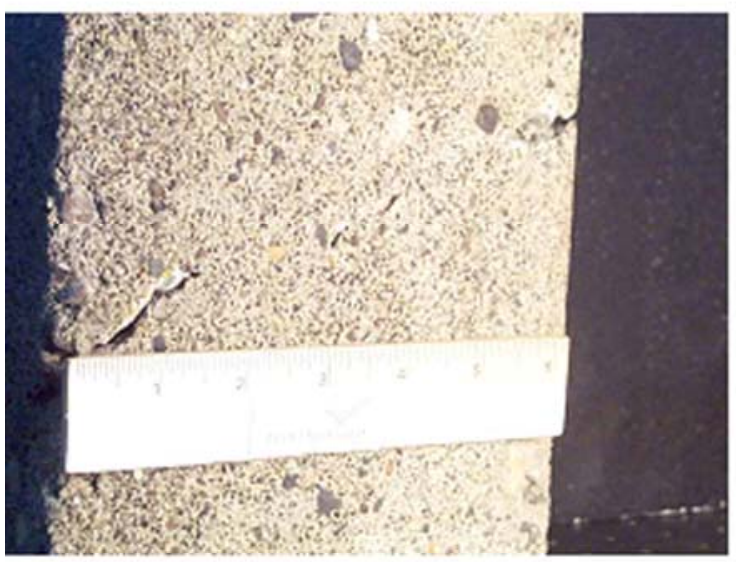

780 nm High Pass

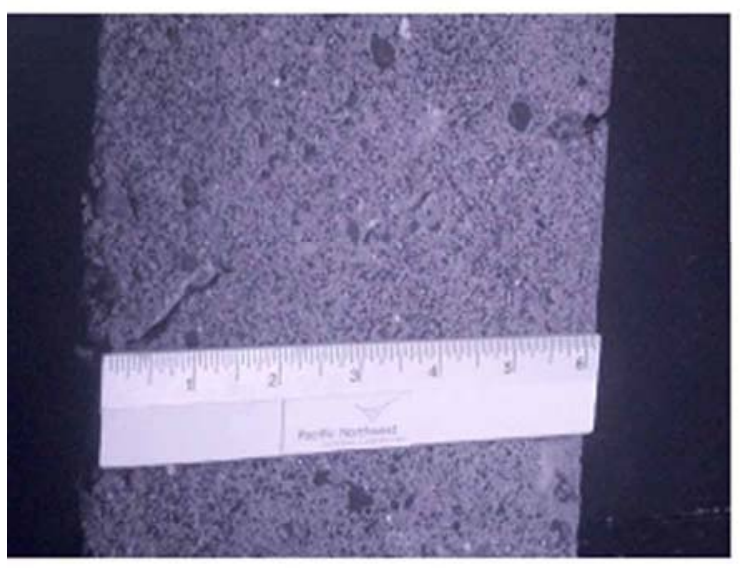

720 nm High Pass

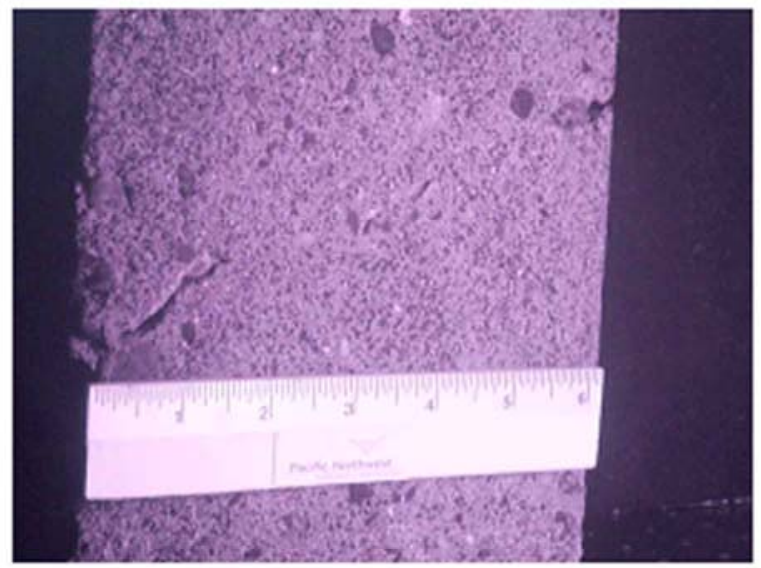

3-5 Micron

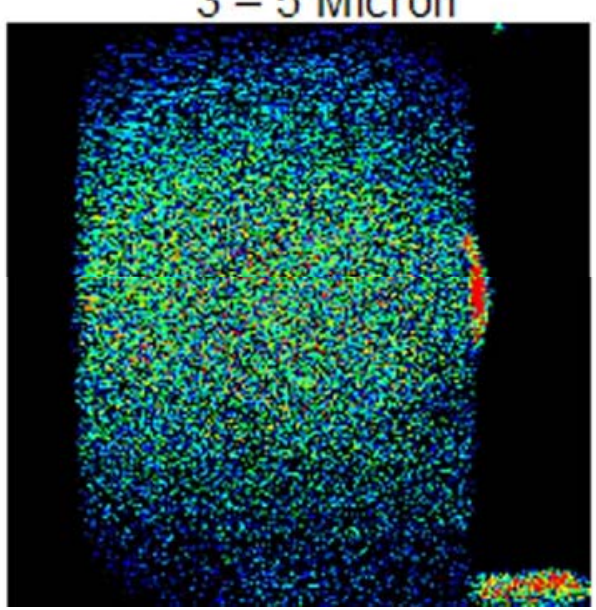

Figure 8. Effect of Image of Crack as a Function of Longer Wavelengths 
Visible

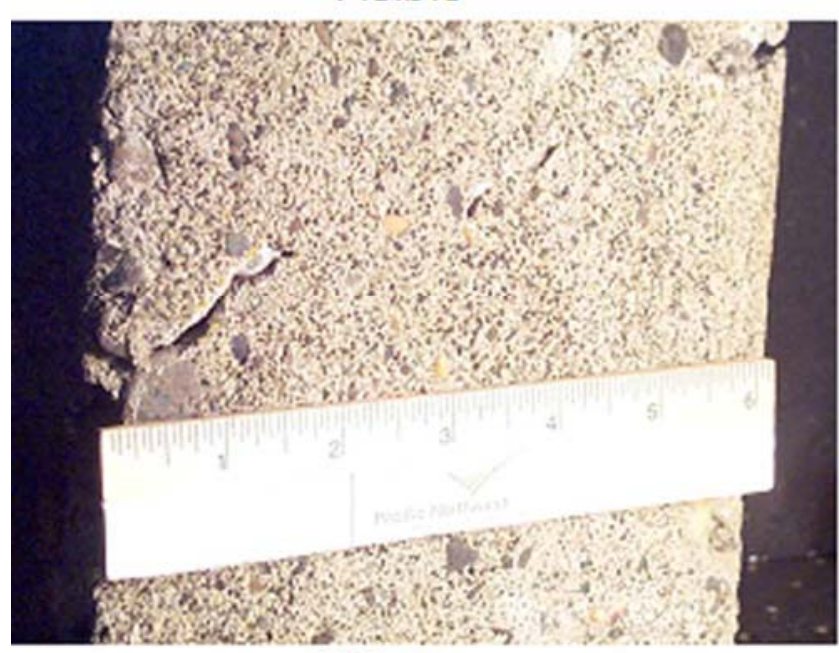

$365 \mathrm{~nm}$

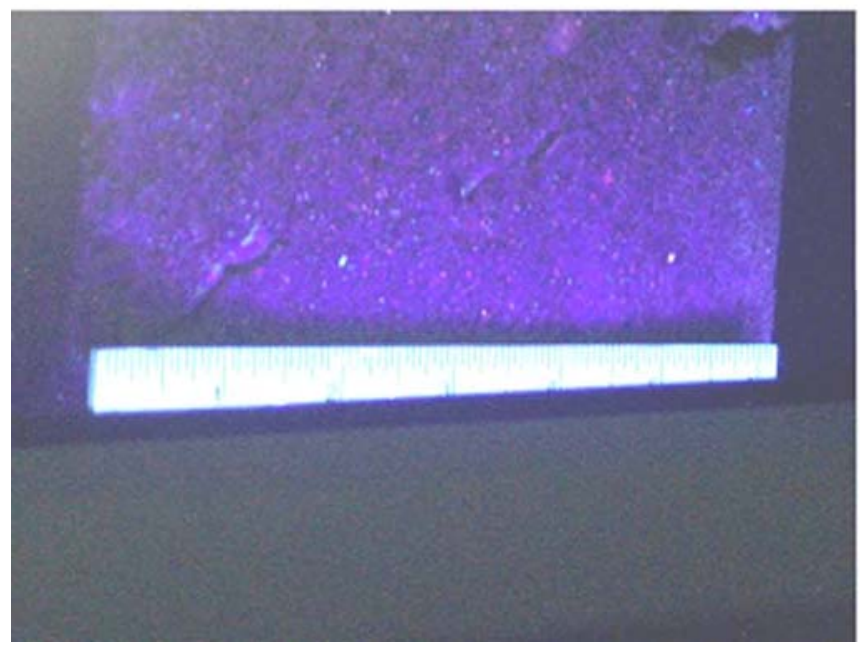

$486 \mathrm{~nm}$

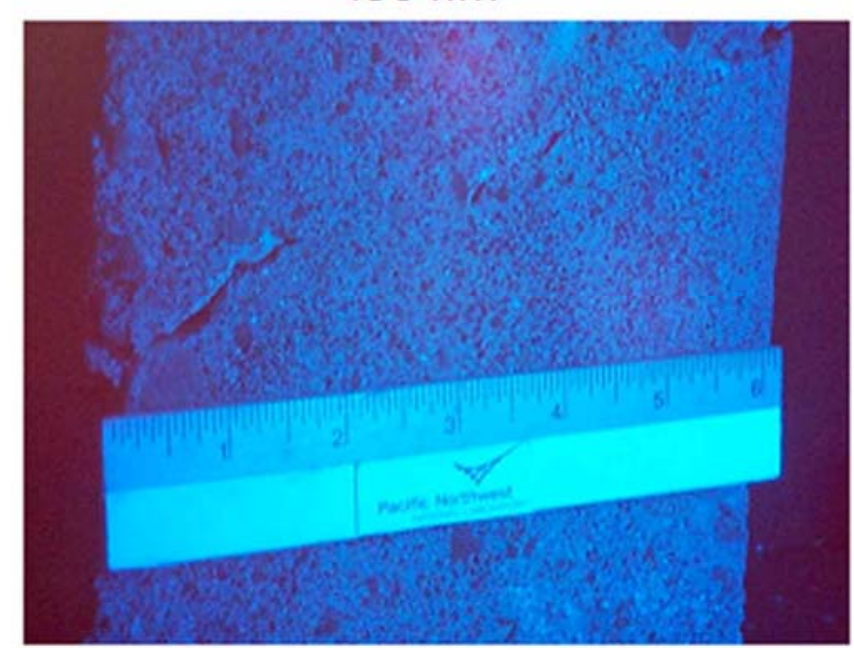

Figure 9. Effect of Image of Crack as a Function of Longer Wavelengths 
Light Source 8 deg, Camera 0

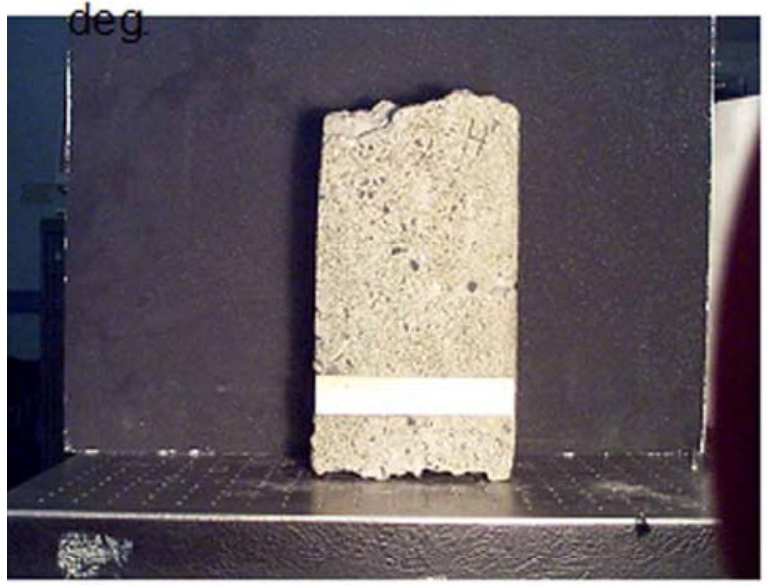

Light Source $47 \mathrm{deg}$, Camera 0 deg

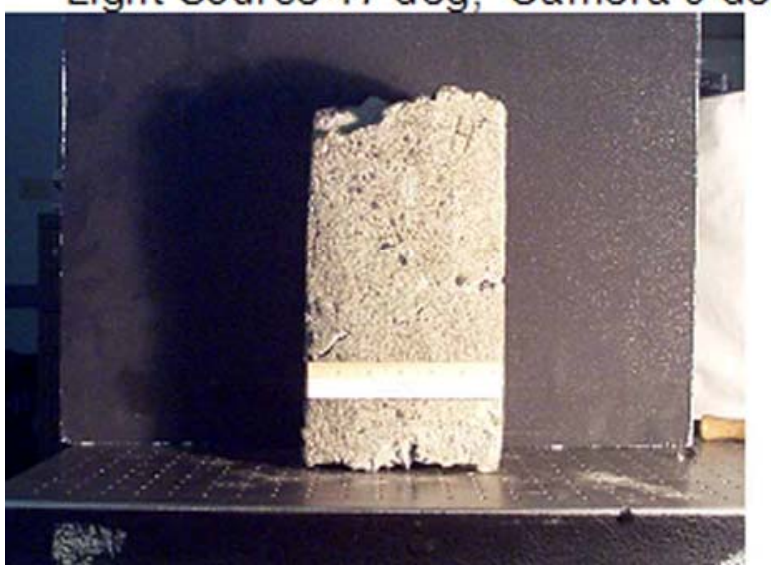

Light Source 34 deg, Camera 0 deg.

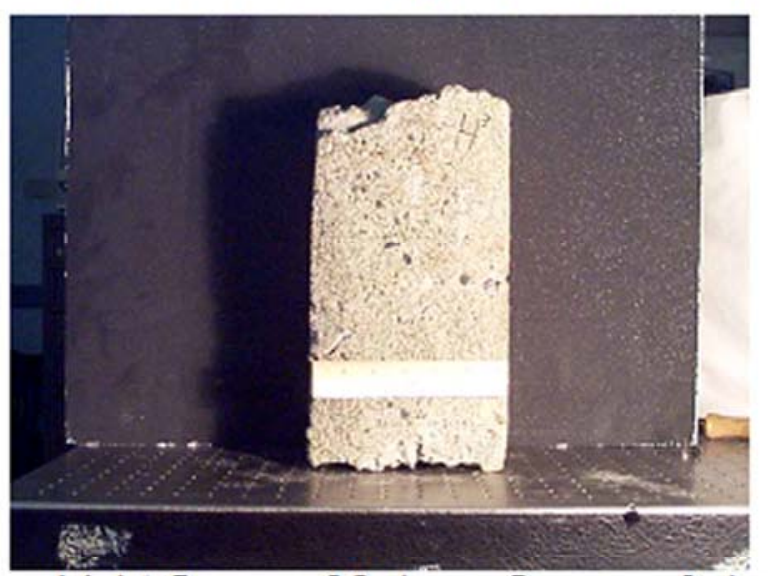

Light Source 62 deg, Camera 0 deg.

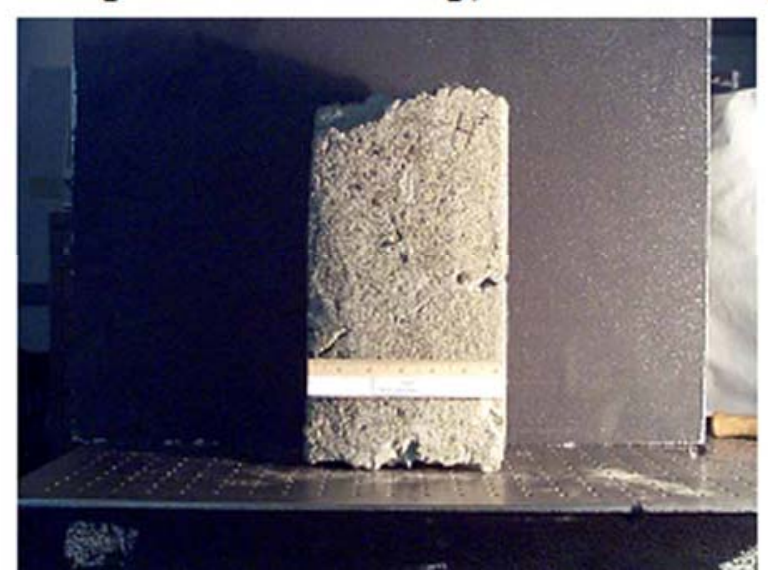

Figure 10. Effect of Light Source Angle on Crack Detection 
Light Source 7 deg. Camera 6 deg.

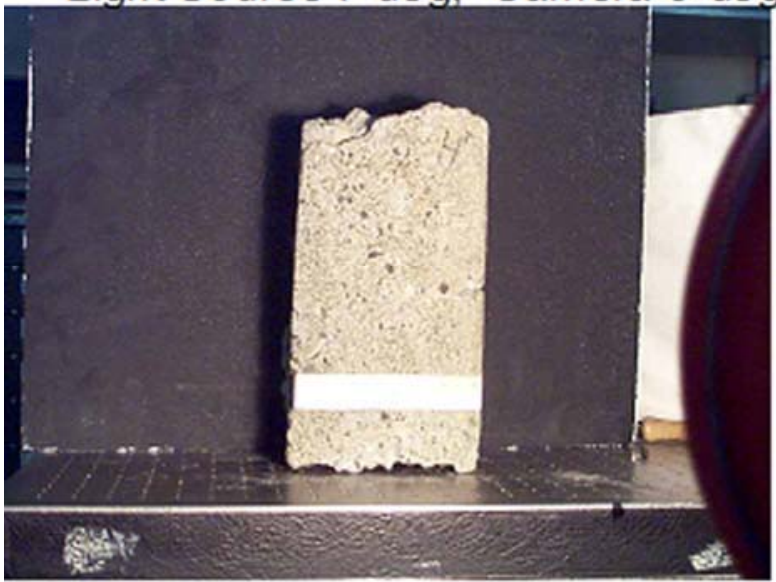

Light Source $7 \mathrm{deg}$. Camera $17 \mathrm{deg}$.

Light Source 7 deg, Camera $41 \mathrm{deg}$.
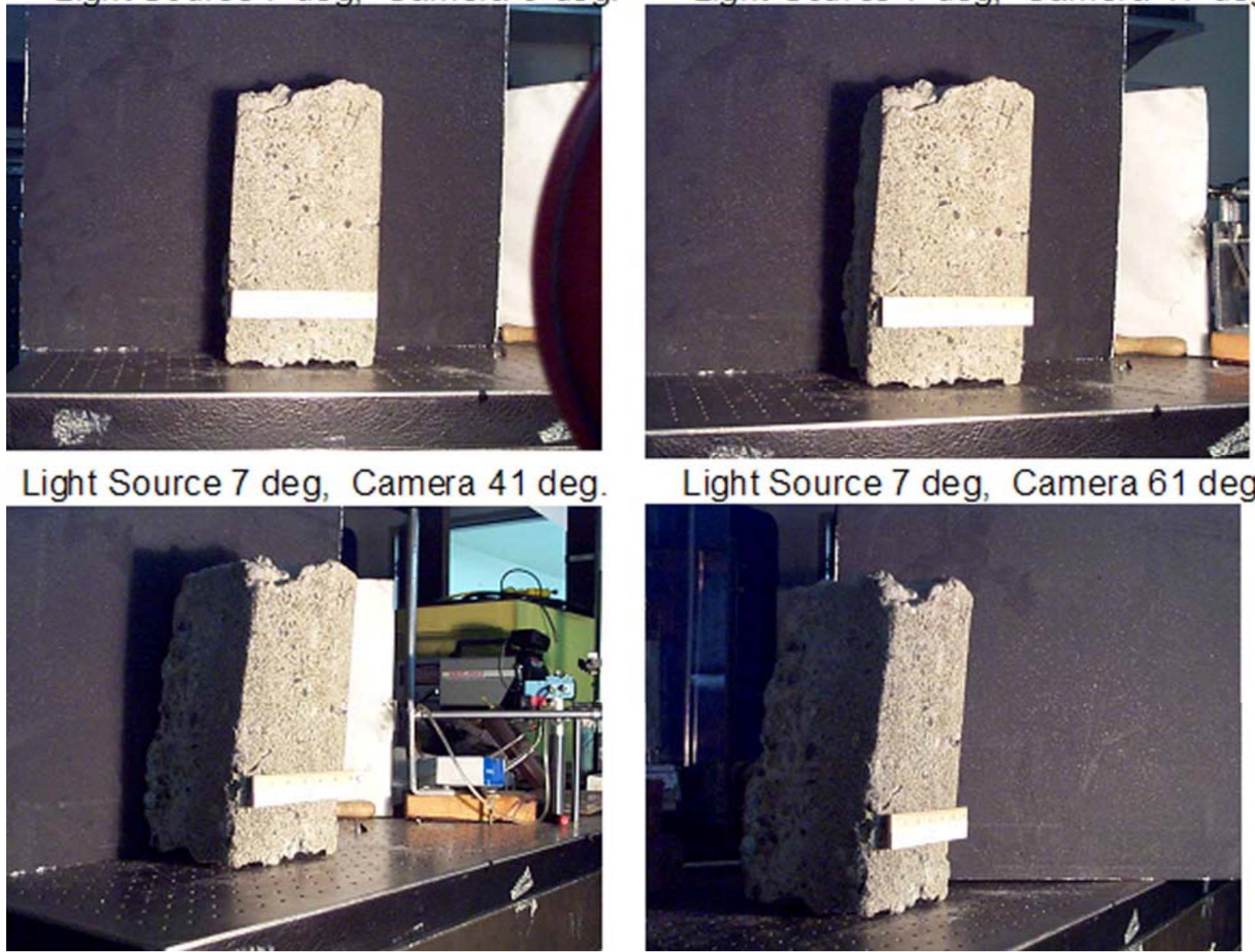

Light Source 7 deg, Camera $61 \mathrm{deg}$.

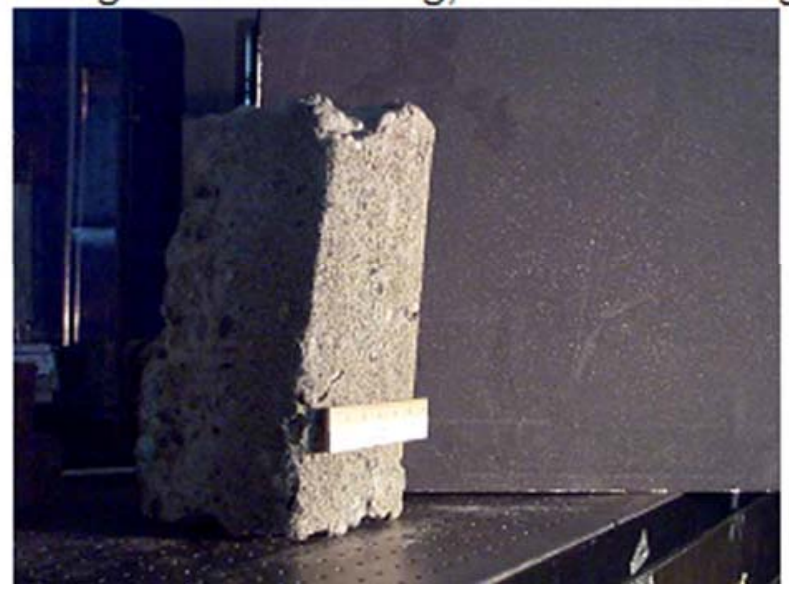

Figure 11. Effect of Camera Angle on Crack Detection 
and the results are shown in Figure 12. In the size of the images that are shown and used for this test, no appreciable change was noted using the different compression formats.

In addition, various image processing techniques can be applied to the image to enhance the crack detection. Several edge filters were applied to the image, and the results are shown in Figures 13 and 14. As can be seen from these images, some of these filters can enhance the detection of a crack in a concrete slab.

Crack detection in the concrete is dependent on how big an area is being examined. The lens is imaging the object onto the pixels in the array, and a crack has to occupy a certain number of pixels in the array in order to be detected. This is illustrated in Figure 15. For this test, a professional digital camera (Canon EOS1) was used for this test. It has 11.1 megapixels in its array, which is 4064 x 2704 pixels, and its size is $35.8 \times 23.8$ $\mathrm{mm}$. The camera was set to compress this image to approximately $1.7 \mathrm{MB}$. A zoom lens, with a focal length of 28 to $35 \mathrm{~mm}$, was used for the lens. The camera was positioned a certain distance away, and the zoom lens adjusted to achieve various field of views in the image.

The detection of the crack is also a function of the size of the picture. This is illustrated in Figure 16, where the same picture is printed in different sizes. One can see that the crack is easily detected as the picture size is increased.

There are other factors that will effect crack detection, such as monitor/printer resolution. All of these parameters need to be accounted for in order to consistently detect the cracks in the concrete.

A test was conducted to determine if one could differentiate between a crack and a line on the concrete. A laser beam, 0.06 in. in diameter, was scanned across the block, onto a line, and onto a crack. The results, shown in Figures 17 through 19, indicate that a crack and a black line on the smooth (red) concrete could be differentiated, but it depended on the size and the intensity of the beam. As shown in Figure 17, if the beam is too intense, one will get a reflection from the sides of the crack that would appear similar to the reflection from a line. Decreasing the intensity of the beam eliminated the peak reflection from the crack. As shown in Figure 18, increasing the size of the crack resulted in the beam being transmitted further into the concrete and resulted in losing the reflection from the crack. The difference between a crack and a line was less pronounced on the rougher concrete, as shown in Figure 19. 


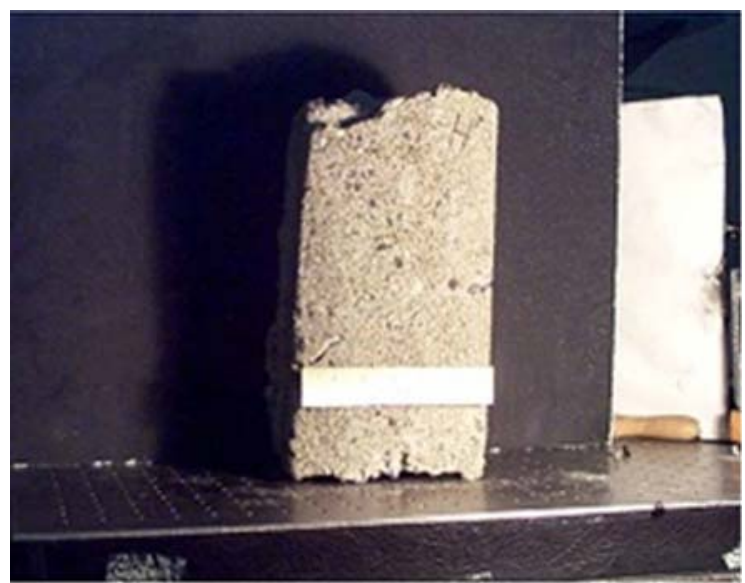

Typical Image (206 KB (jpg))

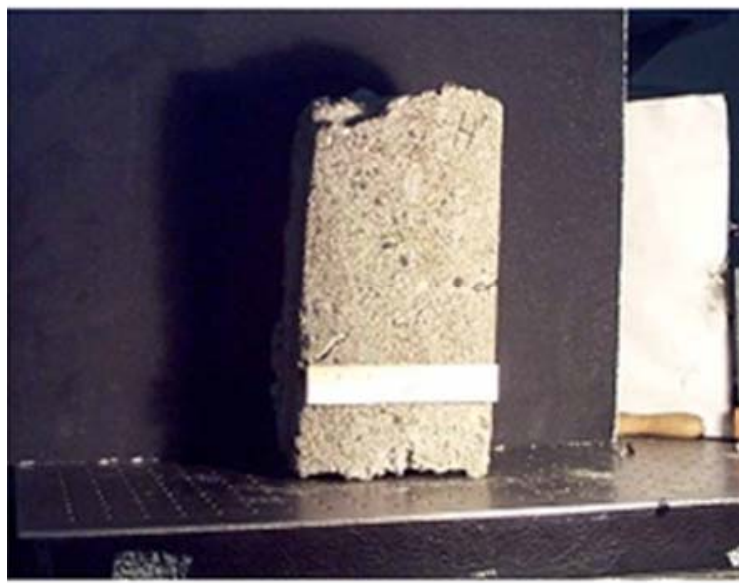

No Camera Compression (192 KB (jpg))

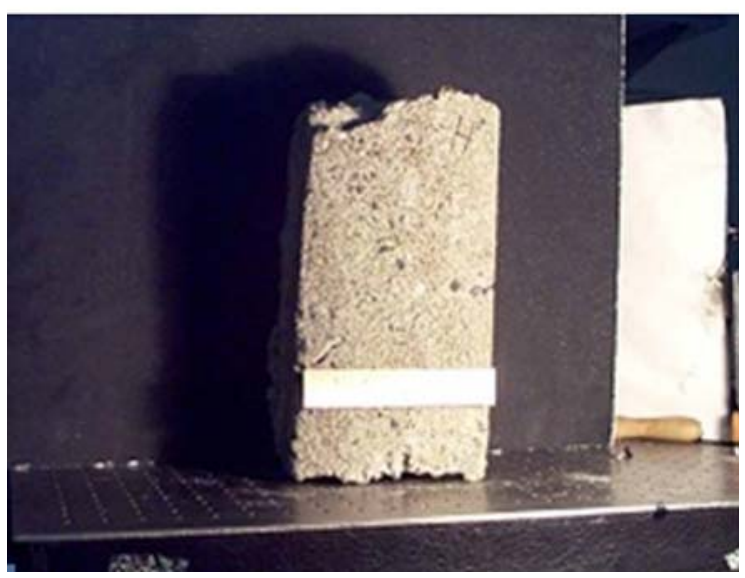

No Camera Compression, Tiff Image (3855 KB)

Figure 12. Effect of Image Compression Techniques on Crack Detection 
Original Image

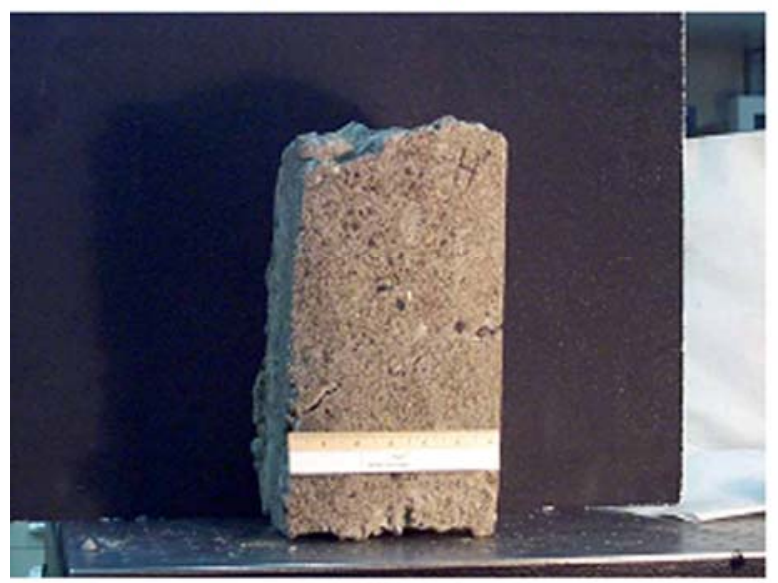

Flatten Filter

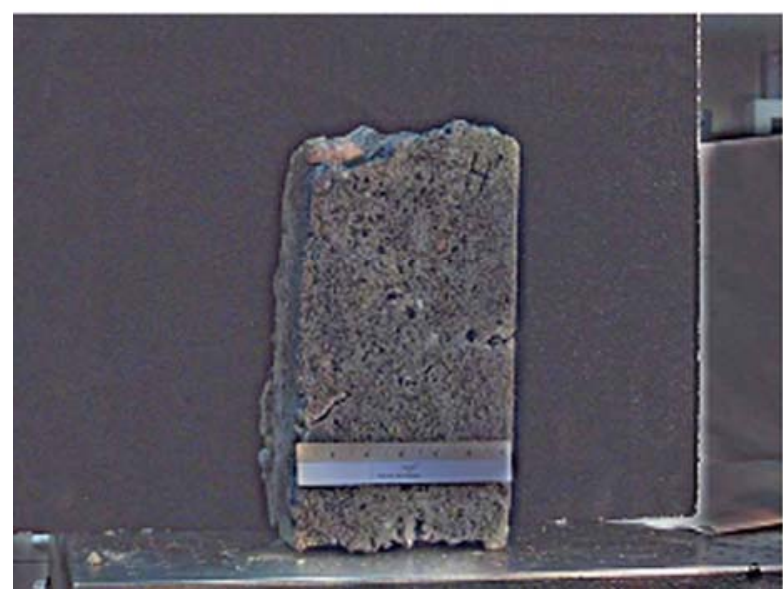

Sculpt Filter

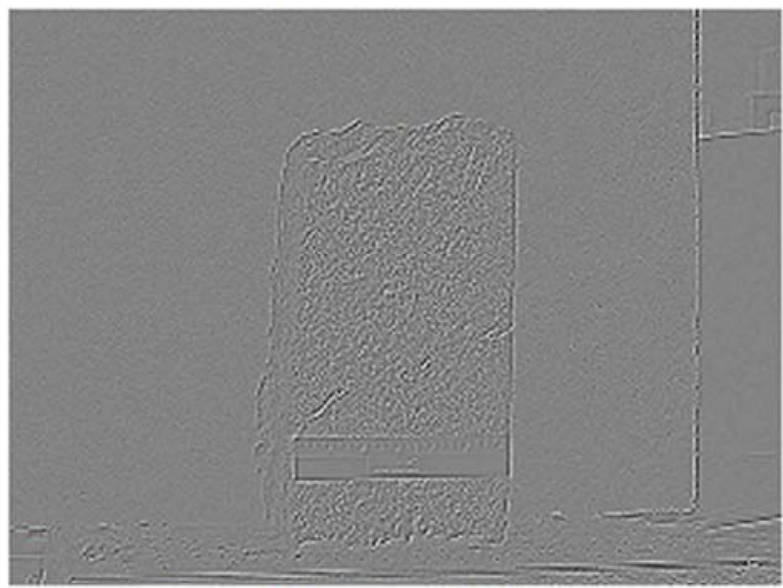

Horizontal Filter

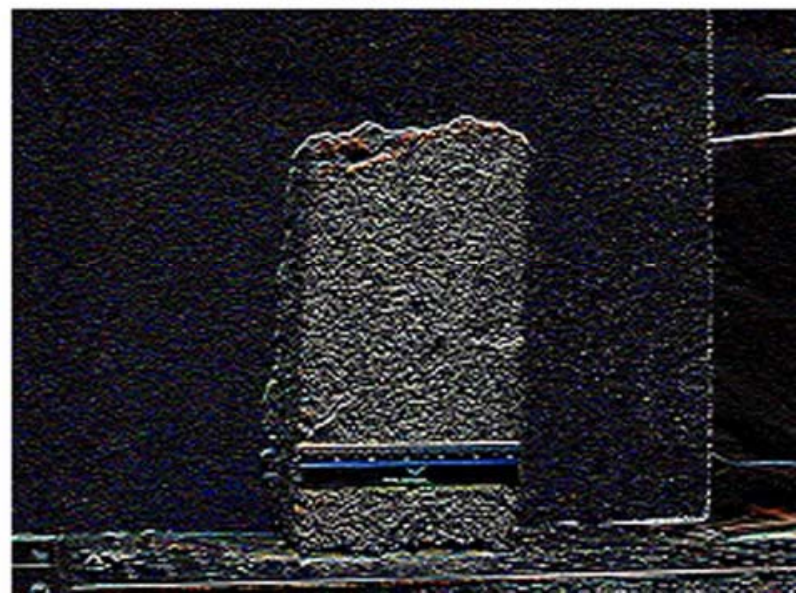

Figure 13. Effect of Applying Image Filters on Crack Detection (A) 
Laplace Filter

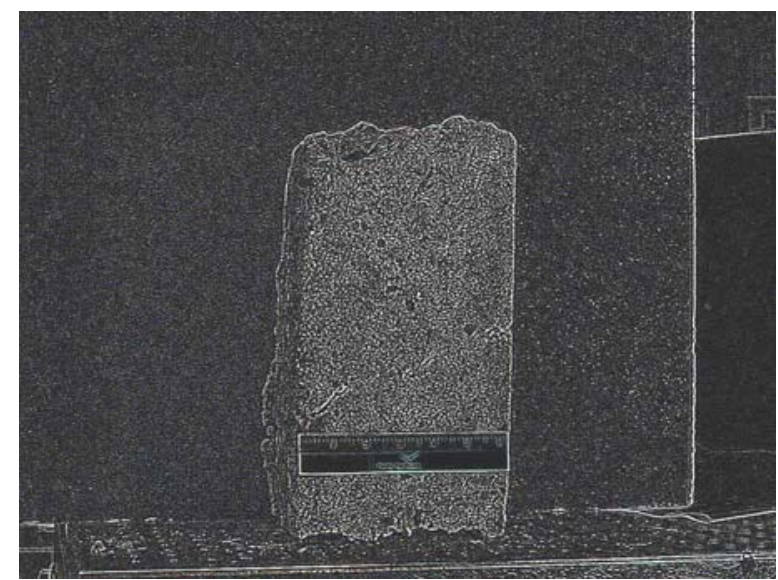

Sobel Filter

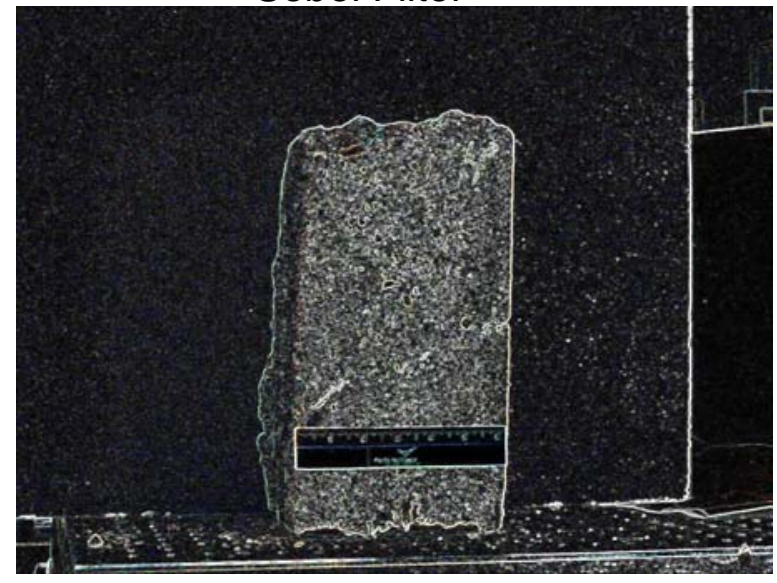

Roberts Filter

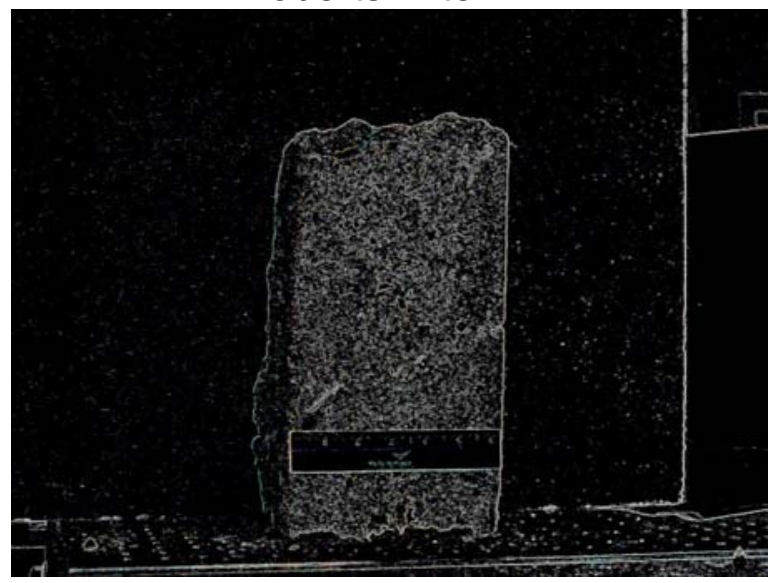

Variance Filter

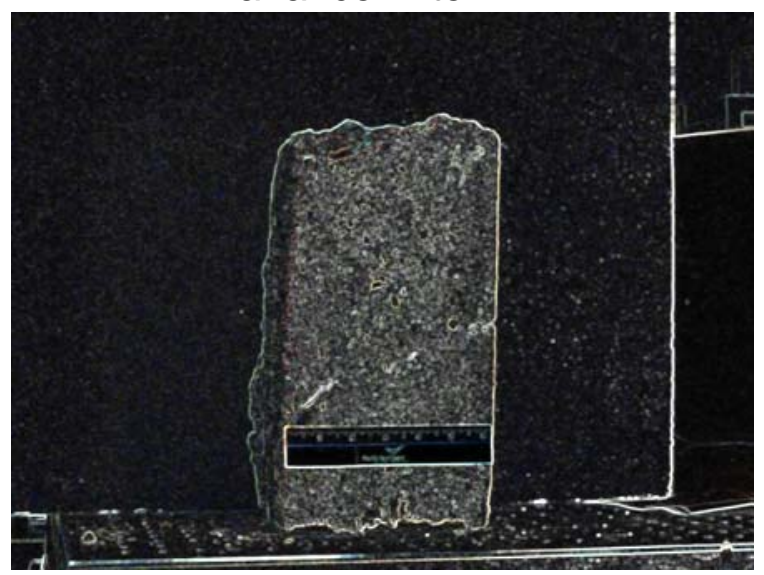

Figure 14. Effect of Applying Image Filters on Crack Detection (B) 
$\mathrm{FOV}=56$ in.

$\mathrm{FOV}=62$ in.

$\mathrm{FOV}=72$ in.

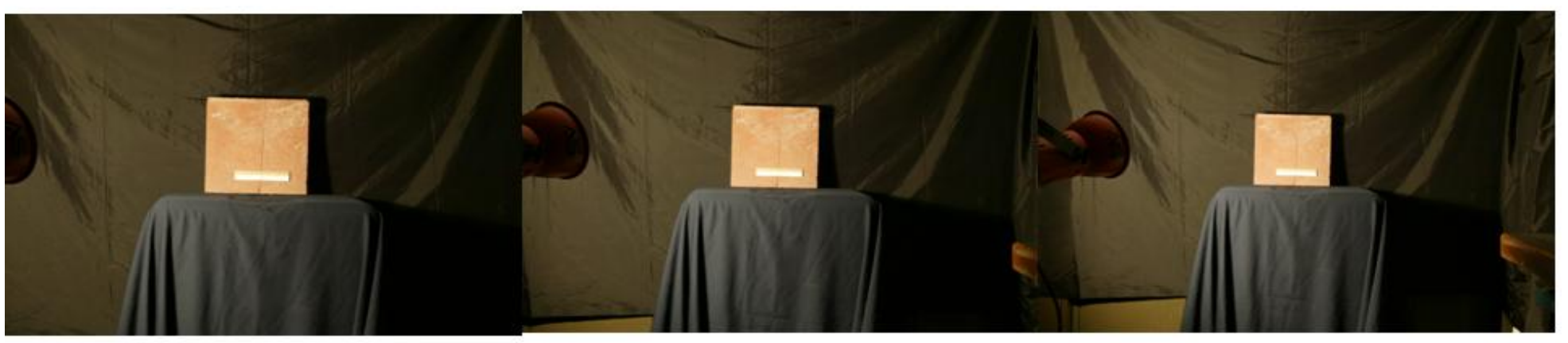

$\mathrm{FOV}=92$ in. $\quad \mathrm{FOV}=101 \mathrm{in.} \quad \mathrm{FOV}=126 \mathrm{in}$.

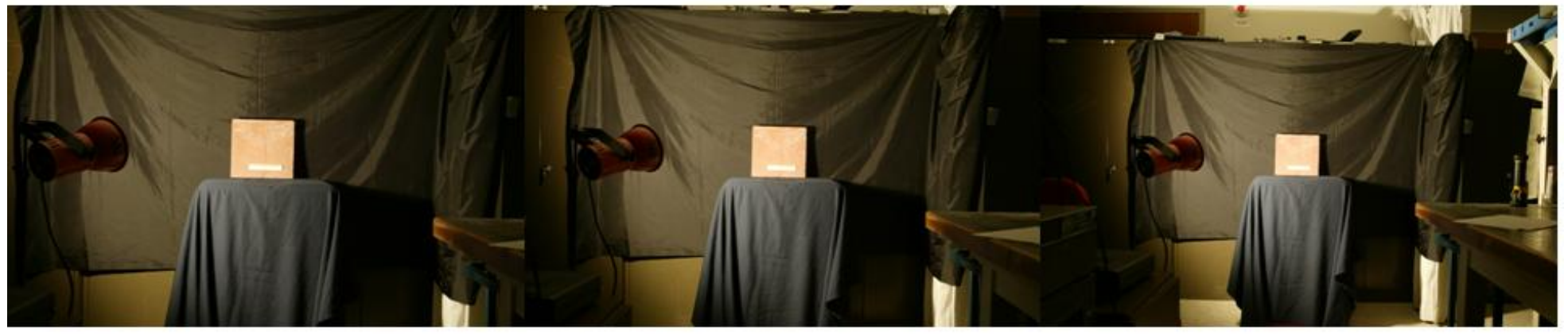

Figure 15. Effect of Field of View on Crack Detection 
Picture Size $=1.7 \times 2.5 \mathrm{in}$

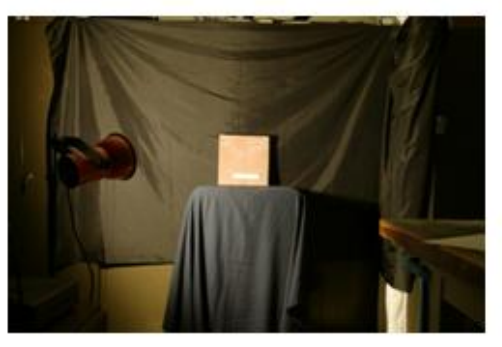

Picture Size $=4 \times 6.1 \mathrm{in}$
Picture Size $=2.8 \times 4.2 \mathrm{in}$

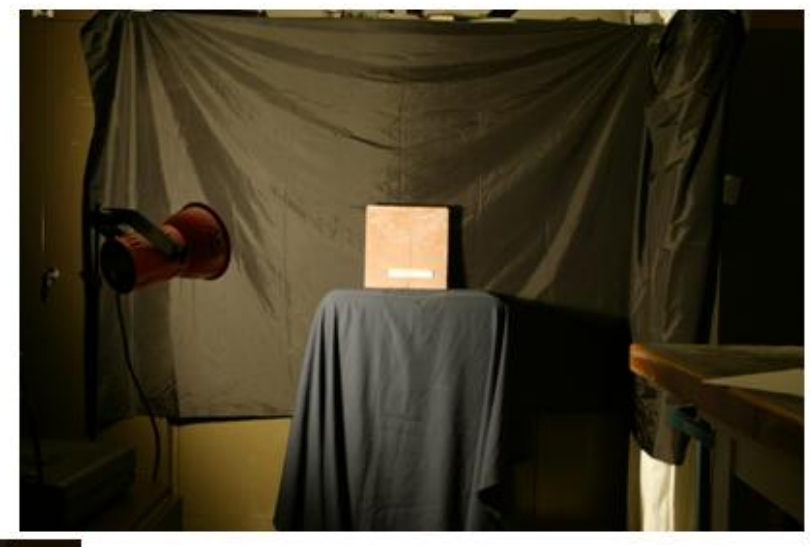

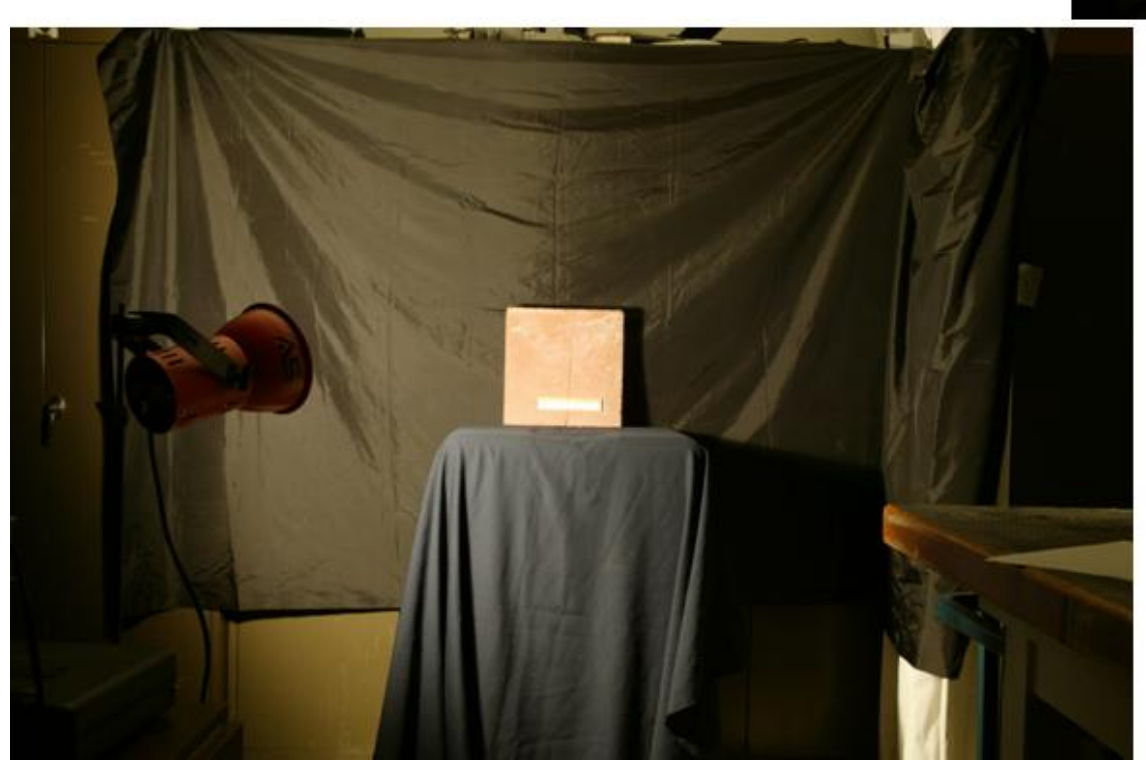

Figure 16. Effect of Picture Size on Crack Detection 


\section{Beam on Block Beam on Black Line Beam in Crack}

(1/16 in. Wide)

$(1 / 16$ in. Wide)

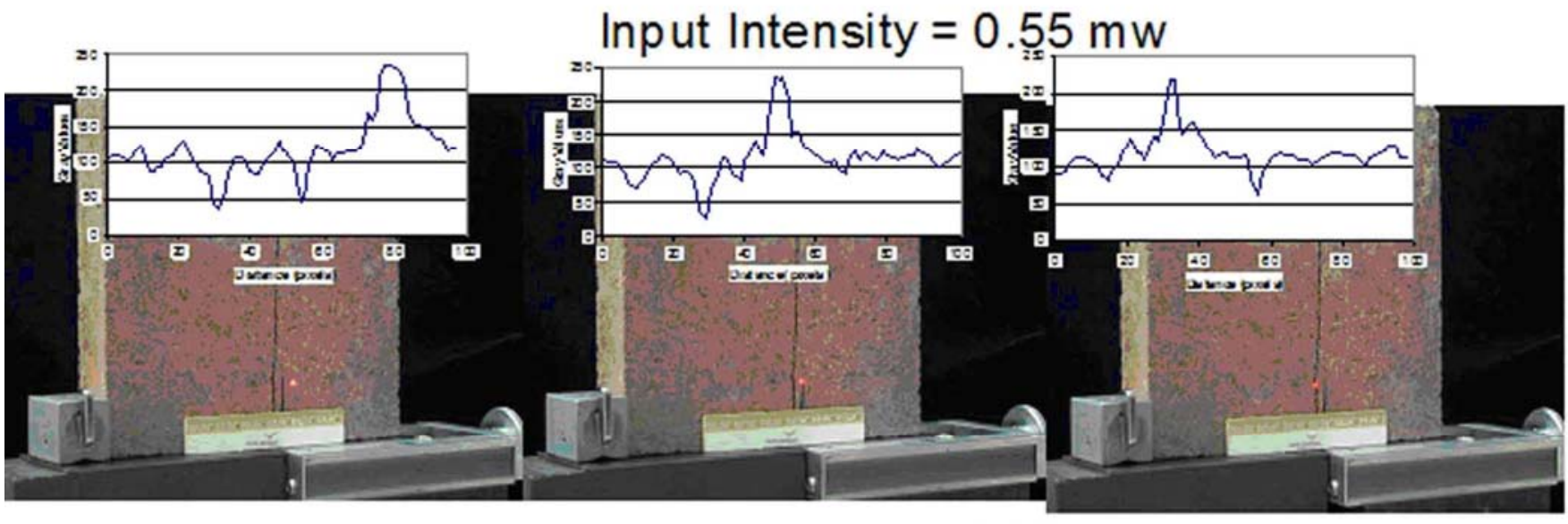

Input Intensity $=0.08 \mathrm{mw}$

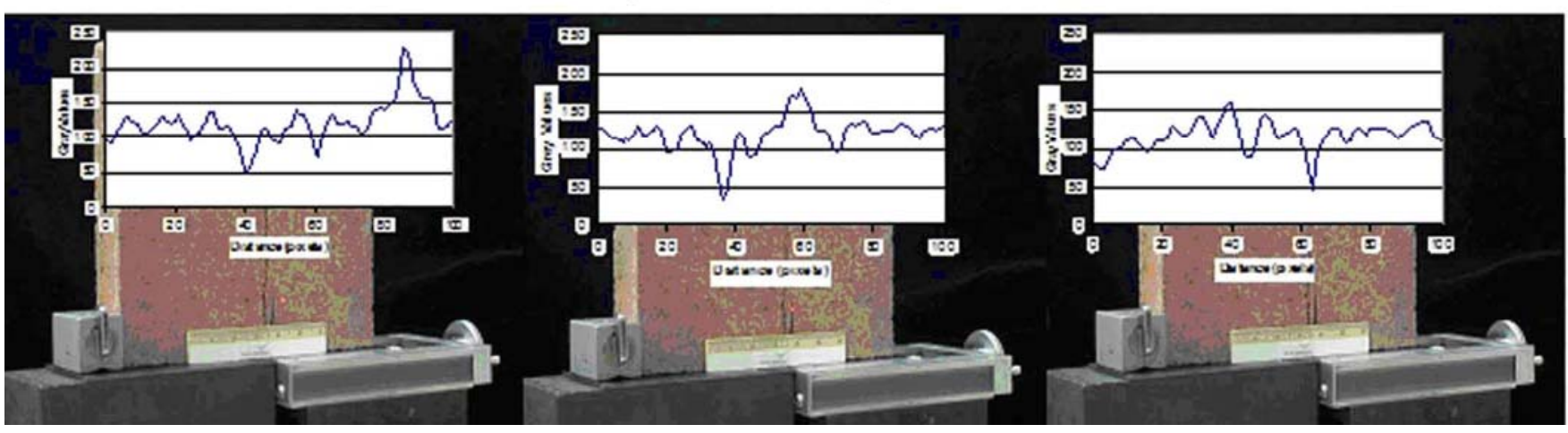

Figure 17. Reflection as a Function of Beam Intensity 

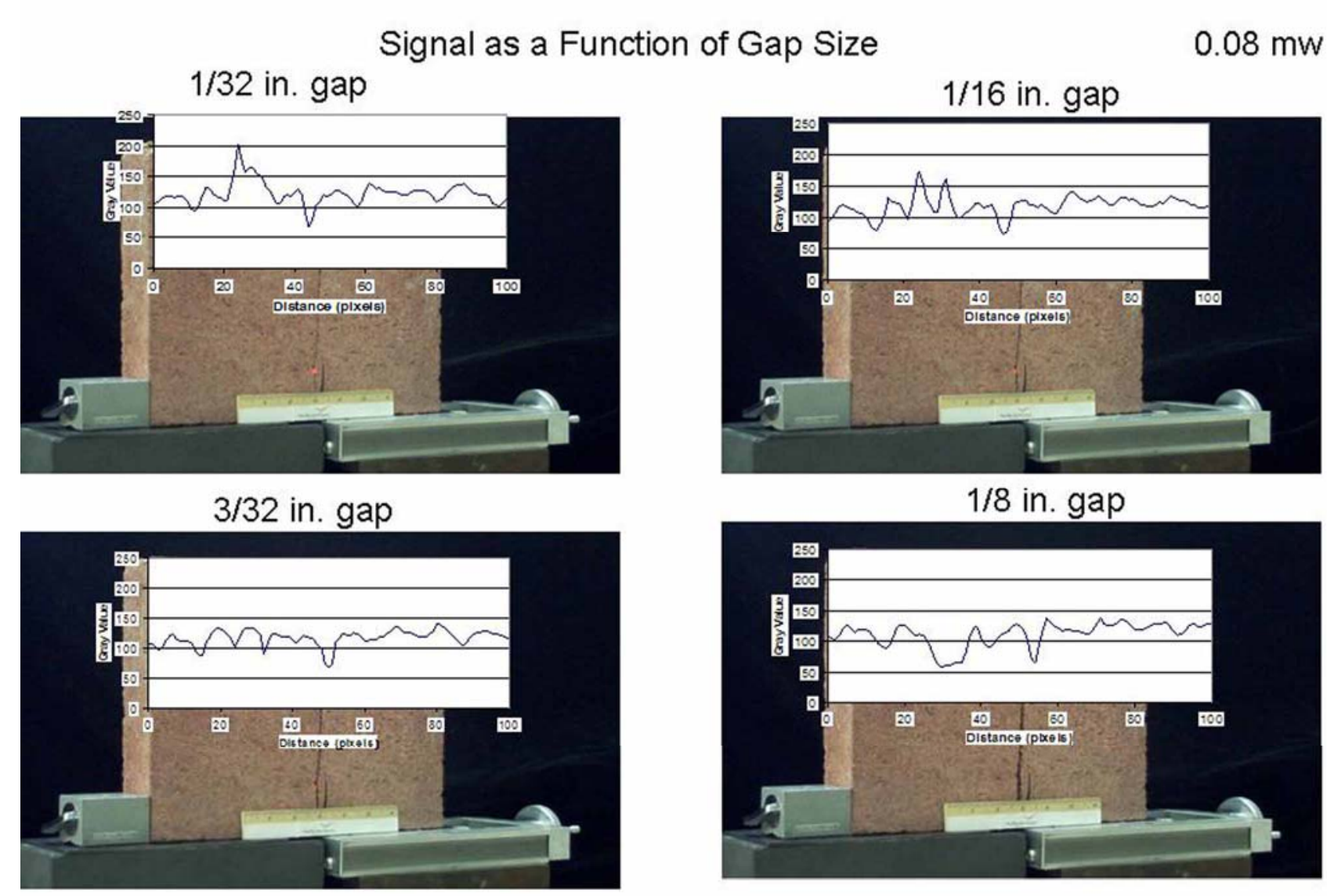

$1 / 8$ in. gap

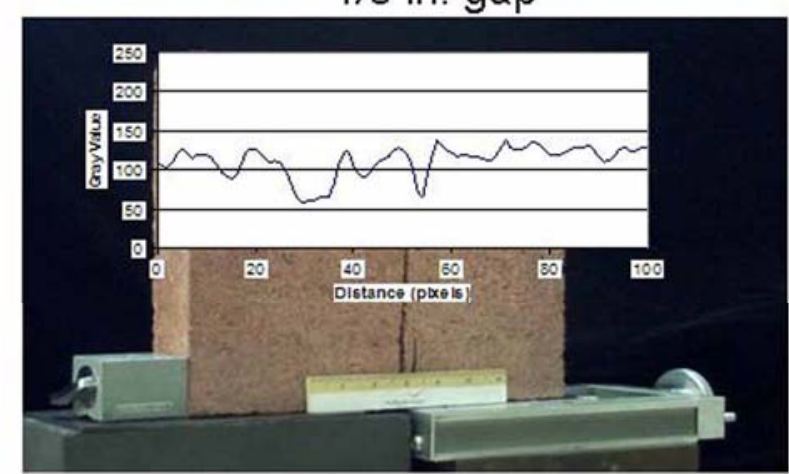

Figure 18. Reflected Signal as a Function of Gap Size 


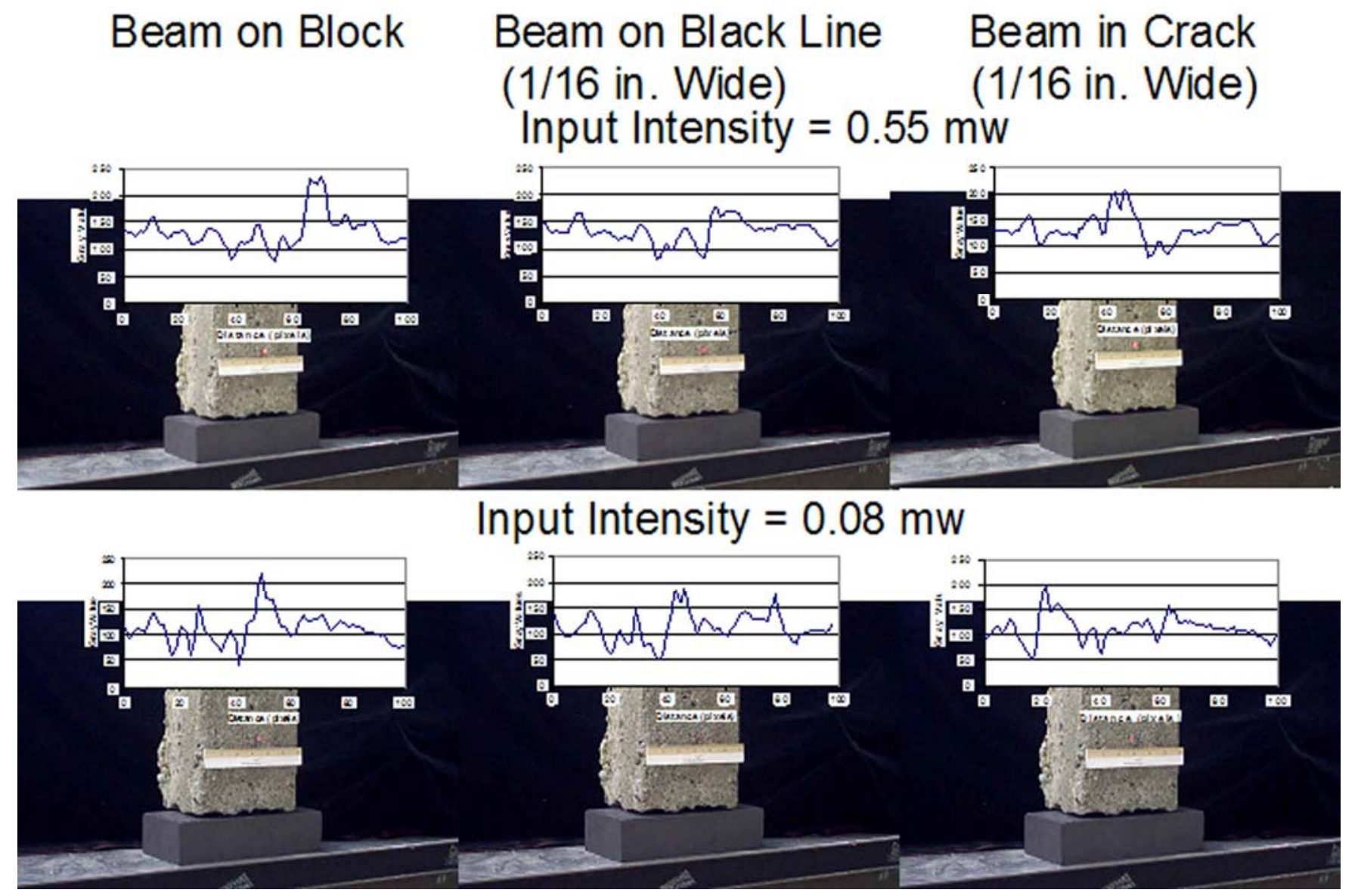

Figure 19. Reflected Signal from Rough Concrete 


\subsection{Surface Profiling}

Commercial systems are available to map surfaces, such as the ceiling of a single shell tank, using optical and acoustic techniques. Engineering studies have determined that a 0.24 in. deflection of a tank dome indicates an early sign of structural distress (RPP-10435, Single-Shell Tank Integrity Assessment Report, Rev. 0, CH2M HILL Hanford Group, Inc., Richland, Washington). Figure 20 shows how one of these devices might be deployed in a tank. Although there are commercial systems that can achieve this level of accuracy, a method to achieve the repeatability of the measurement would need to be developed. If the gage is removed from the tank and placed back in at a later date, some reference marks will be needed to assure that the gage is placed in the exact same position as it was in any previous measurement in order to achieve 0.25 in. repeatability over distance up to 75 feet.

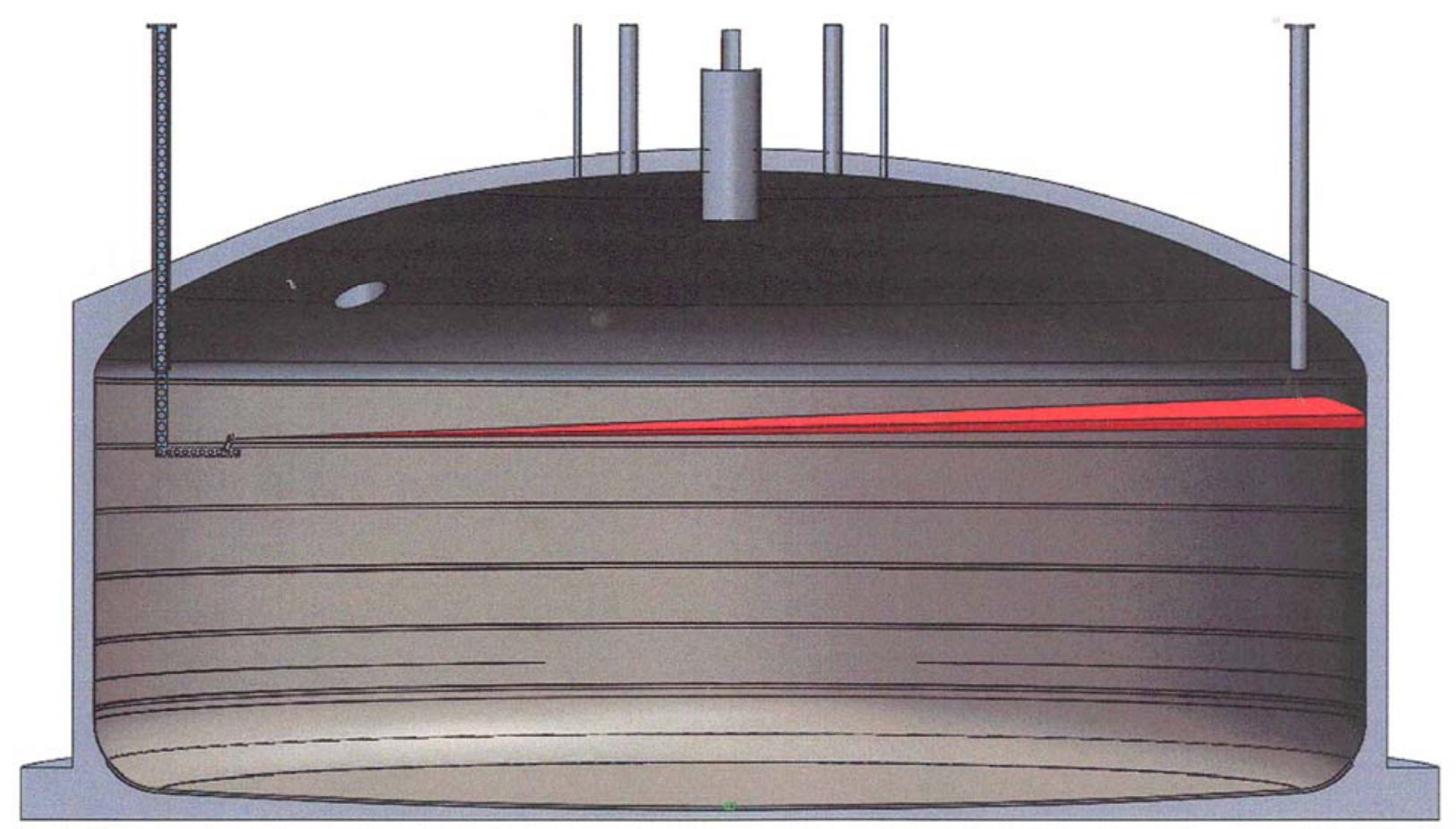

Figure 20. Possible Deployment Scheme for a Remote Measurement Gage 


\subsubsection{Rangefinders}

There are commercial laser range finder systems that can resolve 0.1 in. or better in the ranges that are applicable for waste tank dome inspection. Three possible vendors are Leica Geosystems HDS, which has developed a system for the mining industry, the Acuity Laser Sensors, manufactured by Schmitt Measurement Systems, Inc, and Riegl Laser Measurement Systems. Most of the systems work in the visible or near infrared wavelength regions, so regular optical glass lenses can be used. An example of a laser range finding measurement with the Acuity AR4000 system is the coke drum mapping system shown in Figure 21. Quest Tru-Tec Services uses the AccuRange line scanner to inspect the condition of coke drum vessels. Bulges and cracks in coke drum walls have been a constant problem for many years. Before laser measurement technology, bulge detection and measurement required internal scaffolding and personnel entry into the drum; Quest Tru-Tec's Coke Drum Integrity Assessment program combines a laser mapping technique with a visual inspection via video camera to detect defects in coke drum shells.

A laser distance measurement tool is mounted to a tensioned cable and lowered into the drum. Measurements are taken from the top flange to the bottom cone area. The tensioned cable provides a vertical reference for each scan; therefore, repeatability and comparison of subsequent scans can be used to determine bulge growth rate. Baseline drum scans will provide plant personnel with data that can be used for comparison and determination of bulge growth rates with future scans.

Quest Tru-Tec's laser measurement system acquires up to 10 measurements per square inch. With a Laser Drum Scan, the position and severity of bulges can be easily determined. This information will be reported on a color contour map produced from the scan results. The provided Laser View software precisely pinpoints the position and accurately measures the severity of bulges.

The AR4000 is small in size so that it will fit inside a 12" riser on the tank dome. Special designed equipment will be needed to place the instrument inside the dome. The instrument and related accessories are priced in the $\$ 10,000$ to $\$ 20,000$ range. 


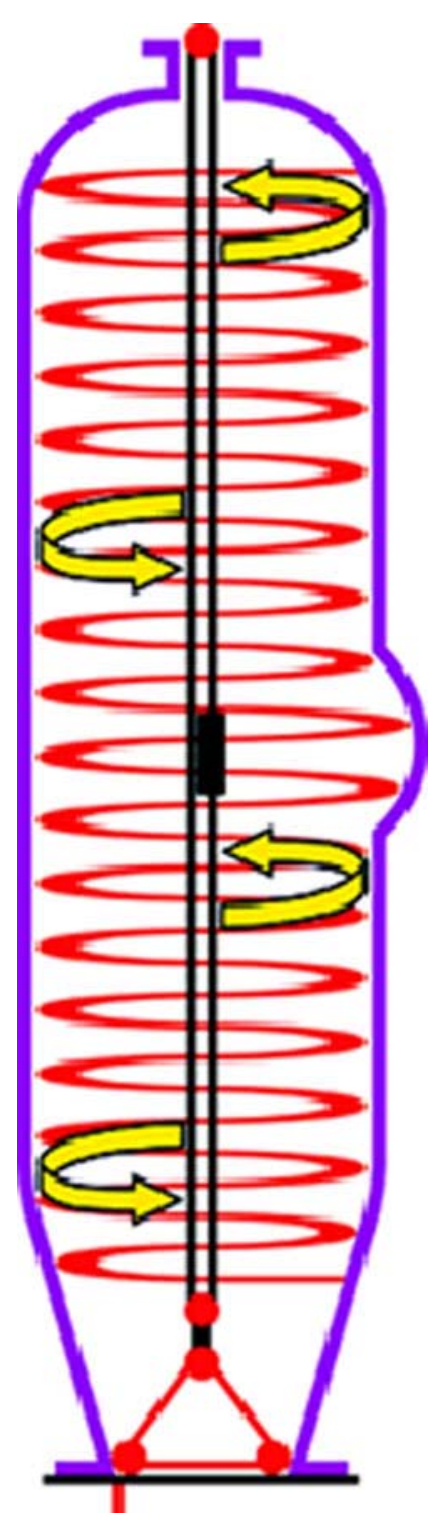

Figure 21. Quest Tru-Tec Laser Measurement System

Acoustic range finder accuracy is usually stated as a percentage of the range. There are commercial systems that can achieve $\pm 0.2 \%$ of the range accuracy. This means to achieve 0.25 inch accuracy, the range cannot exceed $125 \mathrm{in}$. They have a limited field of view, which means they would have to be scanned with the accuracy changing with scan distance.

Commercial radar systems are generally large heavy devices that would be difficult to place through a riser and to scan inside a tank. Some of the system can achieve high measurements accuracies (less than \pm 0.1 in.). 


\subsubsection{Optical Phase Technique}

Farro Technologies, Inc. has developed a laser rangefinder based on the optical phase technique. As with the time-of-flight rangefinders, its accuracy is less than $0.1 \mathrm{inch}$. It is used in the tunnel and mining industry.

\subsubsection{Photogrammetric Techniques}

There are commercial photogrammetric systems, including some that are used in the mining industry that can be adapted for measuring dome sag in a waste tank. One possible system is the Sirovision, developed for the mining industry by the Exploration and Mining division of CSIRO. Photogrammetry was previously done by analyzing photographs, but with the introduction of digital cameras with an increased number of pixels, most of the modern systems use digital imaging. This allows for more automatic processing.

The accuracy of measuring distance using photogrammetric analysis depends on many factors such as the type of camera, the number of pixels in the camera, whether reflective targets are placed on the object, the distance between the camera and the object, etc. As shown in the crack detection section of this report, the wider the field of view of the image, the larger the resolution limit. Geodetic Services, Inc. claims that with reflectors, the points on an object could generally be measured to an accuracy of one part in 300,000, and without target reflectors, the points generally could be measure to one part in 100,000. The accuracy of the readings is also dependent on the base-to-height ratio $(\mathrm{b} / \mathrm{h})$, i.e., the ratio of the distance between the photographs to the distance to the object. If the ratio is too small, small reading errors cause larger errors in depth. If the ratio is above a value of two, then other factors, such as field curvature, begin to affect the accuracy. It should be possible to use photogrammetric techniques to measure changes in the dome position to the desired accuracy. Repeatability of camera positioning would be critical.

\subsubsection{Optical Triangulation Technique}

In the optical triangulation technique, the movement of the line of light on the sensor due to a change in the position of the object is given by the equation:

$$
\Delta \mathrm{x}=-(\mathrm{f} /(\mathrm{l}-\mathrm{f}))(\Delta \mathrm{z}) \sin \mathrm{A}
$$

where:

$\Delta \mathrm{x}=$ change in the position of the spot on the detector due to the change in the object position. 
$\mathrm{f}=$ focal length of the lens in the receiver

$1=$ distance of the receiving system from the object.

$\Delta \mathrm{z}=$ change in the position of the object

$\mathrm{A}=$ angle between the line of sight of the transmitting and receiving optical system.

(See Figure 4 for a further definition of terms).

Applying typical camera values to this equation would indicate that an optical triangulation system could easily measure to the desired accuracy of dome movement. However, note that the accuracy is a function of the angle between the transmitting and receiving optical system and the distance to the object. As a laser beam is scanned across the dome from a fixed location, those two parameters would change, resulting in varying accuracy across the dome. A line could be projected onto the concrete, and the relative position could be determined. Figure 22 shows the results on rough concrete. A camera could record the line profile, and changes

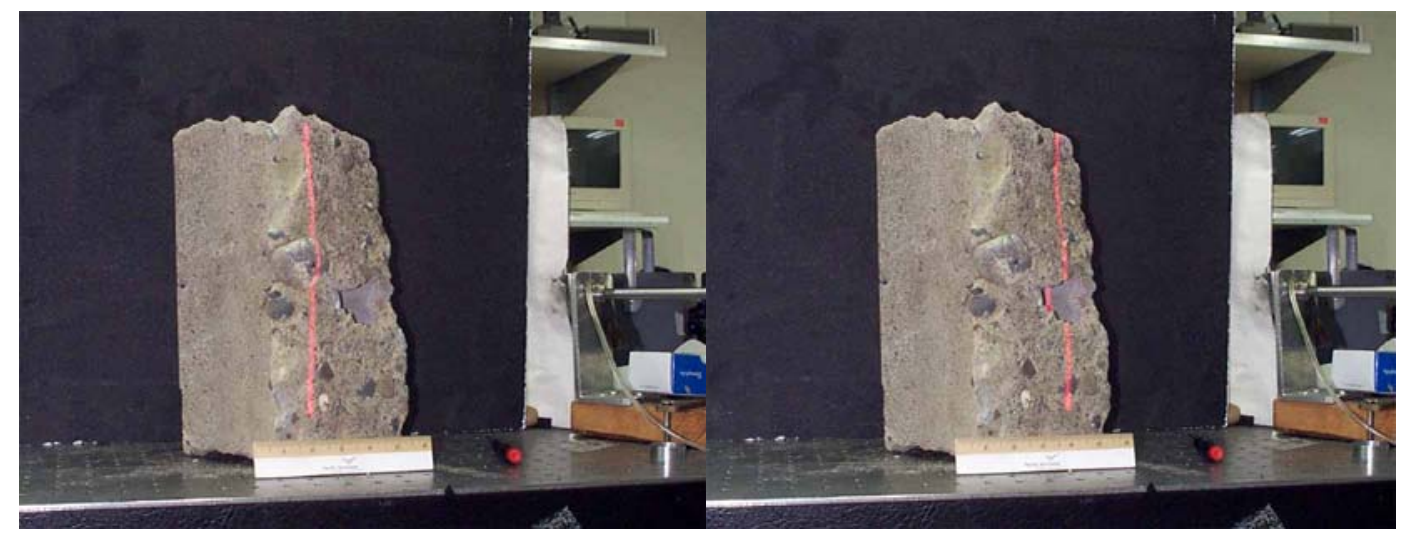

Figure 22: Laser Triangulation Technique on Rough Concrete at 38 Degree Angle

from a known or premeasured shape, could be measured.

There are commercial laser triangulation systems, but a system that could be used in the waste tanks would have to be specially developed. Riegl USA, Inc. has commercial scanning systems that might be able to be used for this application.

\subsubsection{Grid Projection Technique}

Optical triangulation techniques do not necessarily utilize a laser. It is possible to project a line, or a grid, onto an object with an incoherent light source and measure the deviation of the line from a known plane. This was demonstrated in a test shown in Figure 23. The theoretical sensitivity of this technique is described using the following equation: 


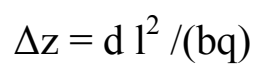

where:

$\Delta \mathrm{z}=$ change in distance to the object

$\mathrm{d}=$ grid spacing in the projection system

$1=$ distance to the object

$\mathrm{b}=$ distance between the projection and receiving system

$\mathrm{q}=$ distance from the projection lens to the grating in the projection system

Like the optical triangulation technique, this technique can have the necessary sensitivity for determining sag in the dome. But also like the optical triangulation technique, it does not give an absolute measurement to the surface, only a relative changes in the surface. The height of at least one point in the picture must be measured to determine the position of the points on the object. In addition, if the wrong grid spacing is chosen, it is possible to lose count of the fringes. Hence, the grating spacing must match the expected changes in the height of the object to avoid ambiguity in the measurement.

Although this is a rather simple system to implement, there are no commercial suppliers of this type of measurement system that were found. It is used in the automobile industry and for other areas where an object needs to be profiled.

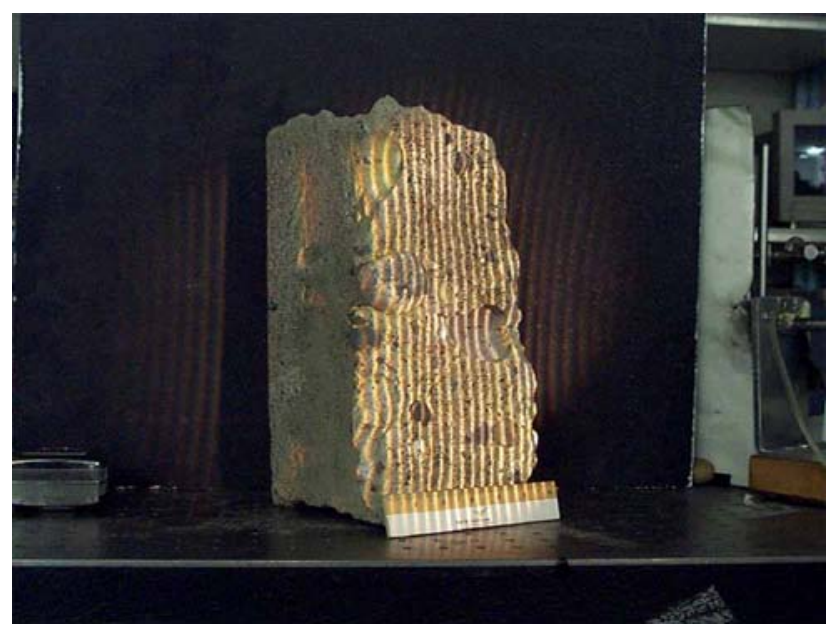

Figure 23. Grid Projection Technique (30 Degree Angle) 


\subsection{Lighting Requirements}

All of the optical schemes involve the use of a light source to illuminate either a point or an area on the ceiling of the waste tank. Factors that will affect the detection of the optical signal will be the sensitivity of the detector, the amount of haze present in the tank atmosphere, the wavelength of the light, the speed (F-number) of the receiving optics, the reflectivity of the surface of the contents, the distance between the source and the detector from the surface, etc..

A brief analysis was conducted to determine the amount of light that is required to illuminate an area in the waste tank. Assume that the detector is twelve feet away from the surface and the area to be examined is eight feet in diameter. If the detector is treated as an array, such as in a video camera, then the minimum light sensitivity of the device is about $3.34 \times 10^{-7}$ watt $/ \mathrm{cm}^{2}$. Generally, one would like to operate at least a factor of ten greater than this value to minimize the effects of noise, so for this analysis we will assume that the minimum irradiance (H) needed to detect an area on the surface is $10^{-5}$ watts $/ \mathrm{cm}^{2}$.

The radiance on the surface to achieve this amount of irradiance at the detector is given by the equation:

$$
\mathrm{N}=4 \mathrm{~F}^{2} \mathrm{H} /(\pi \mathrm{T})
$$

where:

$$
\begin{aligned}
& \mathrm{N}=\text { radiance at the surface of the contents } \\
& \mathrm{F}=\mathrm{F} \text {-number of the optical detection system } \\
& \mathrm{H}=\text { required irradiance at the detector } \\
& \mathrm{T}=\text { transmission of the atmosphere and optical system }
\end{aligned}
$$

Using the previous assumptions, $\mathrm{F}=1 /(2 \sin 180)=1.62$.

$$
\begin{aligned}
& \text { Using } \mathrm{H}=10^{-5} \text { watts } / \mathrm{cm}^{2} \text {, and } \mathrm{T}=90 \% \text {, yields: } \\
& \qquad \mathrm{N}=3.7 \times 10^{-5} \text { watts }\left(\mathrm{cm}^{2}-\text { steradian }\right)
\end{aligned}
$$

Then the irradiance required at the edge of the lighted area, $\mathrm{H}_{27}$, in order to achieve this radiance from the surface is given by:

$$
\begin{aligned}
\mathrm{H}_{27} & =\pi \mathrm{N} / \mathrm{r} \\
\text { where: } \quad \quad \mathrm{r} & =\text { reflectivity of the surface }
\end{aligned}
$$


If we assume the reflectivity of the surface is $50 \%$, then $\mathrm{H}_{27}=2.2 \times 10^{-4}$ watts $/ \mathrm{cm}^{2}$. The irradiance of the surface directly under the light source, $\left(\mathrm{H}_{0}\right)$ which is assumed to be located next to the detector, is given by:

$$
\begin{aligned}
\mathrm{H}_{0} & =\mathrm{H}_{27} / \cos ^{4} 180 \\
& =2.8 \times 10^{-4} \text { watts } / \mathrm{cm}^{2} .
\end{aligned}
$$

The intensity $(\mathrm{J})$ of the light source required to achieve this irradiance on the surface is given by:

$$
\mathrm{J}=\mathrm{H}_{0} \mathrm{R}^{2} / \mathrm{T}
$$

where: $\quad \mathrm{R}=$ distance from the surface to the light source

$$
\mathrm{T}=\text { Transmission of the atmosphere and optical system }
$$
associated with the light source.

If we assume that $\mathrm{R}=12 \mathrm{ft}(366 \mathrm{~cm})$ and $\mathrm{T}=80 \%$, then $\mathrm{J}=47.1$ watts $/$ steradian. Then the flux emitted by the source $(\mathrm{P})$ is given by:

$$
\mathrm{P}=2 \pi \mathrm{J}=296 \text { watts. }
$$

This could easily be achieved by a light source.

Shadowing will always be a problem if there are large and abrupt changes in the surface. In addition, other risers and obstructions that protrude into the vapor space may block the light or the receiver. To resolve this issue, it would probably be necessary to place a measurement system in more than one riser. 


\subsection{Conclusions}

\subsection{Crack Detection}

Researchers can detect and analyze a 1/16 in. crack in the concrete dome of a waste tank when viewed near a riser. A high-resolution digital camera, similar to those used by professional photographers, could achieve this kind of resolution. Lighting is critical, as well as image size and matching the lens requirements to the resolution requirements. The lens would probably have to be a remotely controlled zoom lens in order to keep the resolution constant as the camera is scanned from a fixed location. The camera could be operated in a low resolution video mode, and then snap and download high resolution images to a computer. Also critical to the success of the crack detection technique is the size of the image. Image enhancement techniques, such as edge detection, may be used to assist in crack detection.

\subsection{Surface Profiling}

There are several methods that can be used to map the dome of a waste tank to determine sag or movement in the dome. Table 1 summarizes the advantages and disadvantages of the various methods. Employing these techniques in more than one riser would probably be necessary due to obscurations and shadowing effects. For example, if a riser protrudes from the dome, it would block some area of the dome being measured from a fixed location. An alternative would be to use a robotic arm. Because the dome is fairly smooth, shadowing effects (where a bump on the surface will block the beam from viewing a surface next to the bump) should not be a significant problem. More details on system requirements would need to be provided to determine the best method to be employed. For example, some of these techniques could not be used in tanks that have heavy fog. 
TABLE 1. Comparison of Various Sensor Systems

\begin{tabular}{|c|c|c|}
\hline$\underline{\text { Sensor }}$ & Advantages & Disadvantages \\
\hline Acoustic & $\begin{array}{l}\text { High resolution }( \pm 0.02 \text { in.) } \\
\text { Inexpensive }(\$ 1500) \\
\text { Not effected by poor visibility } \\
\text { Small and lightweight } \\
\text { Operates in fog }\end{array}$ & $\begin{array}{l}\text { Limited range ( } 5 \text { feet }) \\
\text { Only examines a small area } \\
\text { Determines distance only to the } \\
\text { closest point in the area } \\
\text { Better suited for robotic arm }\end{array}$ \\
\hline $\begin{array}{l}\text { Laser } \\
\text { Range- } \\
\text { finder }\end{array}$ & $\begin{array}{l}\text { Narrow beamwidth } \\
(0.0060-0.0280) \\
\text { Good resolution (less than } 0.1 \mathrm{in} .) \\
\text { Very large depth of field }\end{array}$ & $\begin{array}{l}\text { Generally used for longer ranges } \\
\text { Needs good visibility }\end{array}$ \\
\hline Radar & $\begin{array}{l}\text { High radial resolution }( \pm 0.01 \text { in.) on } \\
\text { wet surfaces } \\
\text { Intrinsically safe systems are } \\
\text { commercially available } \\
\text { Large depth of field ( } 130 \mathrm{ft} .) \\
\text { Operates in fog }\end{array}$ & $\begin{array}{l}\text { Expensive } \\
\text { Large and heavy } \\
\text { Scanning mechanism needs to be } \\
\text { developed } \\
\text { Large beamwidth }(3-100) \\
\text { Does not detect dry surfaces unless } \\
\text { use millimeter waves }\end{array}$ \\
\hline $\begin{array}{l}\text { Photo- } \\
\text { gram- } \\
\text { metric }\end{array}$ & $\begin{array}{l}\text { High resolution }( \pm 0.04 \text { in.) } \\
\text { Easily employed using existing waste } \\
\text { tank procedures } \\
\text { Stereoscopic views are possible } \\
\text { Actual photographs can be viewed } \\
\text { Data manipulation possible with } \\
\text { computer systems. }\end{array}$ & Need good visibility \\
\hline $\begin{array}{l}\text { Optical } \\
\text { Trian- } \\
\text { gulation }\end{array}$ & $\begin{array}{l}\text { Well established technology } \\
\text { Good resolution } \\
\text { Small beamwidth ( } 0.1 \text { in.) }\end{array}$ & Needs good visibility \\
\hline $\begin{array}{l}\text { Optical } \\
\text { Phase }\end{array}$ & $\begin{array}{l}\text { Good resolution } \\
\text { Small beamwidth ( } 0.1 \text { in.) }\end{array}$ & $\begin{array}{l}\text { Needs good visibility } \\
\text { Output frequency of laser diode very } \\
\text { dependent on external temperature }\end{array}$ \\
\hline $\begin{array}{l}\text { Grid } \\
\text { Pro- } \\
\text { jection }\end{array}$ & Surface contours readily visible & $\begin{array}{l}\text { Data difficult to interpret - better } \\
\text { suited for detecting contour changes } \\
\text { Needs good visibility }\end{array}$ \\
\hline
\end{tabular}

